\title{
Does Competition Affect Giving? An Experimental Study*
}

\author{
John Duffy ${ }^{\dagger}$ \\ Department of Economics \\ University of Pittsburgh \\ Pittsburgh, PA 15260, USA
}

\author{
Tatiana Kornienko $\ddagger$ \\ Department of Economics \\ University of Stirling \\ Stirling FK9 4LA, UK
}

This Draft: July 2005

\begin{abstract}
We explore whether natural human competitiveness can be exploited to stimulate charitable giving in a controlled laboratory experiment involving three different treatments of a sequential "dictator game." Without disclosing the actual amounts given and kept, in each period players are publicly ranked - by the amount they give away, by the amount they keep for themselves, or spuriously. Our results are generally supportive of the hypothesis that competitive urges can encourage or frustrate altruistic behavior, depending on the competitive frame. We find some support for an alternative hypothesis that relative concerns are due to information-gathering rather than competition.

JEL classification numbers: C91, D64

Keywords: Dictator game, repeated decisions, charitable giving, altruistic behavior, competitive altruism, status, relative standing, tournaments, motivation, informationbased relative concerns.

*Much of work on this paper was done while the second author was a member of the Economics department of the University of Manitoba, Canada. We would like to thank Ted Bergstrom, Ed Hopkins, Martin Sefton, and Lise Vesterlund for useful comments and suggestions, and Charles Kannair, Scott Kinross, Kristin Kleinjans, and Nicolas Rosenfeld for help running the experiment. Duffy acknowledges financial support from the National Science Foundation. Kornienko acknowledges financial support from a UM/SSHRC research grant, from the Faculty of Arts of the University of Manitoba, and from the Faculty of Management of the

$\dagger$ jduffy@pitt.edu, http://www.pitt.edu/ jduffy

†tatiana.kornienko@stir.ac.uk, http://staff.stir.ac.uk/tatiana.kornienko
\end{abstract} University of Stirling. 
"I talked to both Bill Gates and Warren Buffett, the two richest men in the country, and they would be inclined to give more if there was a list of who did the giving rather than the having." $\quad$ Ted Turner (as quoted by Dowd [1996])

\section{Introduction}

Media mogul Ted Turner suggested that natural human competitiveness might be exploited to stimulate charitable giving, by publicizing the charitable contributions made by the largest U.S. givers. As Dowd [1996] described Turner's idea, "Why not start an annual list of the most generous, offering an "Ebenezer Scrooge Prize" that embarrasses stingy billionaires and a "Heart of Gold Award" to honor philanthropists?" If winning a generosity tournament confers some rank or social status, competitive altruism might counteract competitive selfishness. This suggestion prompted the creation of Slate magazine's list of the most generous Americans, as an antithesis to Forbes magazine's list of the wealthiest Americans.

Can competition affect charitable giving? According to Becker [1974], Andreoni [1990] and others, charitable giving can be readily explained without resorting to extrinsic concerns for relative position, by supposing that individuals get a selfish "warm glow" from the amounts of their charitable contributions. The more individuals give away, the more "warm glow" they receive, the better their sense of well-being, ceteris paribus.

However, we live in a world where interpersonal comparisons are possible and, increasingly, publicly available (as in the lists of Forbes and Slate), and there is ample evidence that charities exploit such comparisons in their fund-raising efforts. For instance, Glazer and Konrad [1996] observe that charities frequently publish the names of contributors providing various threshold amounts of giving in clearly defined, rank-ordered categories with labels such as "contributor", "benefactor" etc. (in lieu of reporting the actual amounts given), and they develop a model in which individuals can signal their unobservable income via the level of their giving. Harbaugh [1998] uses empirical data on charitable contributions grouped by threshold categories to estimate a utility function that can differentiate between intrinsic motivations and extrinsic concerns for "prestige," and reports that both factors play a role in the amounts given.

Here we pursue an alternative and complementary approach, reporting on a controlled laboratory experiment aimed at understanding whether unselfish, philanthropic behavior responds to competitive urges. By contrast with field or survey data, laboratory experimentation affords greater control over the information that is available to individual decisionmakers, thereby heightening the effects of different information conditions (tournament structures), that comprise our treatment conditions. Specifically, we study behavior in a sequential "dictator game" in which individuals are anonymously paired and one member of each pair - "the dictator" - unilaterally determines how to allocate a given endowment (\$10 per de- 
cision round) between himself and his unique "match" (a person who is in another room). Following each of 10 decision periods, we report to groups of dictators information regarding their performance relative to other dictators in their group in terms of their ordinal rank. If selfish individuals respond to the incentives provided by comparisons of their performance to that of other people, then the manner in which information on relative standing is presented - "the frame," in the terminology of psychologists, (e.g. Kahneman and Tversky [1979]) is of crucial importance.

We explore the effect of three "frames" or "treatments" which differ in the information revealed to players. Following each round of the "Selfish" treatment, groups of subjects see a rank list of the IDs of members of their group, arranged in descending order according to the amounts that group members chose to keep for themselves in that round. Following each round of the "Altruistic" treatment, groups of subjects see a rank list of the IDs of members of their group, arranged in descending order according to the amounts that group members gave to their match in that round. In a third, "Control" treatment, ranks are randomly assigned at the end of each round and the spuriousness of these ranks is public information. Subjects were specifically instructed that their earnings were unaffected by their rank. While subjects were informed of their rank, they were uniformed of the individual dollar amounts kept/given by other dictators as we wanted to avoid the effect that such information might have on the development of social norms of keeping/giving. ${ }^{1}$ In addition, rankings are reported using subject ID letters, which are private information. This avoids confounding individual intrinsic, competitive motives with extrinsic desires for status/social acclaim or with a desire to impress the experimenter. If subjects' giving is malleable, even by the weak competitive incentives of our design, then it seems likely that it will be even more malleable in non-anonymous environments, e.g., among the "Ted Turner crowd" of large donors. Indeed, experimental studies of the role played by "status" or "social acclaim" (e.g. Ball, Eckel, Grossman and Zame [2001], Pingle et al. [2003] or Kumru and Vesterlund [2004]) find that such factors have substantial effects. ${ }^{2}$ Finally, we note that in the dictator game we adopt, each subject in the dictator role has a unique matched partner to whom they can allocate a part of their endowment. This design avoids free-riding (public good) problems that might arise, e.g., if groups of players (dictators) were deciding how much to give to a single charity.

Our findings suggest that subjects respond to being placed in a competitive environment

\footnotetext{
${ }^{1}$ The latter design feature is also consistent with the practice by charities of grouping contributions into rank-ordered categories as noted above, perhaps for the same reason we give.

${ }^{2}$ One intrinsic motive that might explain the behavior we observe could be non-instrumental (intrinsic or hard-wired) concern with status (in the sense of Postlewaite [1998]), in which individuals compete with each other just for the sake of competing, rather than in order to acquire valuable goods (see Veblen [1899], Frank [1985a]). That would imply that if individuals are hard-wired to excel, then when placed in a competitive environment they should behave competitively. We admit that our experiment is not a pure test of such "intrinsic" incentives; as with other studies exploring the effects of relative concerns, it is not free from "experimenter demand" or "Hawthorne" effects. Nevertheless, we believe that the anonymity of subjects in our design minimizes these demand effects, and that our design based on relative rankings is more readily replicated than the experimental studies that have sought to induce concerns for social acclaim.
} 
even when there is no extrinsic benefit from competition. On average, those in the Selfish treatment kept the largest amounts of money for themselves (and thus gave away the least), while those in the Altruistic treatment kept the smallest amounts of money for themselves (and thus gave away the most). The amounts kept by those in the Control treatment lie in between. However, there is considerable heterogeneity across players in all treatments.

For the Selfish and Altruistic treatments, we use the directional adjustment of subjects' giving in response to updated information on their relative rank to classify subjects' behavior into types. We find that there exist a sizable proportion of subjects who are responsive to the Altruistic competitive frame. It is the behavior of these "Altruistic-Competitive" subjects who are largely responsible for the aggregate differences among the frames, as these subjects gave away on average $\$ 5.60$, or $56 \%$ of the funds. In other words, for some subjects competition does stimulate giving! In the Selfish treatment, as the competitive motives enhanced the pecuniary ones, the "Selfish-Pecuniary/Competitive" subjects decreased their giving over time, giving, on average, $\$ 0.86$, or $8.6 \%$ of the funds - quite close to equilibrium predictions of the classical dictator game, and contributing to the general decline in giving over time in the Selfish treatment. Even more interesting however, is that in the Altruistic treatment, there are some "Altruistic-Pecuniary" subjects as well, whose behavior is not statistically different from that of the Selfish-Pecuniary/Competitive subjects in the Selfish treatment; such subjects gave an average of $\$ 1.21$, or $12.1 \%$ of the funds and are responsible for the general decline in giving over time that is observed in the Altruistic treatment. Importantly, the phenomenon of decreasing giving over time is not observed in the Control treatment. It thus appears that "learning to give less" relies heavily on the social information provided in the Altruistic and Selfish treatments and not so much on "second thought," introspective reasoning. ${ }^{3}$

This is a striking finding and it calls for an explanation about what else could be happening in the treatments with socially relevant information over and above any competitive and simple pecuniary considerations. While achieving higher ranks improves one's chance of winning a competition, relative comparisons also serve as a source of information about the state of the environment, and thus allow for social learning (Samuelson [2004]). We therefore speculate that some subjects may care about behaving in a socially acceptable way. Subjects may or may not have own beliefs about what is socially acceptable and what is not, and they may look for keys or signals based on others' behavior. The relative rankings, in tandem with some experimentation, may provide information on the level of giving that is socially acceptable - at least among members of the same group.

Our work also contributes to the growing literature on intrinsic versus extrinsic motivations. Economists have accumulated strong empirical evidence that economic performance is enhanced by intrinsic, selfish competitive urges (see, for example, the survey by Weiss and Fershtman [1998]). While a majority of economic contests are designed so that interpersonal competition further promotes self-regarding behavior, there have been few attempts to use

\footnotetext{
${ }^{3}$ See Weber [2003] for the experiments on subjects' learning in the absence of feedback.
} 
tournament-like environments to alter other-regarding behavior. ${ }^{4}$

Yet as recent research suggests, the relationship between intrinsic and extrinsic motivations is complex; extrinsic motivations may encourage or frustrate intrinsic motivations. Gneezy and Rustichini [2000] report a striking finding that, when extrinsic, (i.e., monetary) incentives are "too small" they may hinder intrinsic motivations, but when "large enough" extrinsic motivations may have the opposite effect, following the general pattern of a "W" (see more on this in Gneezy [2003]). Benabou and Tirole [2003] further identify circumstances where explicit incentives may reinforce or weaken intrinsic motivations. Thus, most of the literature on the relationship between extrinsic and intrinsic motivation explores how monetary (extrinsic) incentives may weaken or enhance non-monetary (intrinsic) motives. ${ }^{5}$ Here we explore the opposite, that is, we explore how non-monetary, intrinsic motives (the desire to compete) may weaken or enhance monetary motives. Indeed, we find that the desire to compete (for competition's sake) reinforces or weakens altruistic behavior in a predictable direction.

The remainder of the paper is organized as follows. Section 2 presents a simple model of competitive behavior in the three treatments and provides some comparative static predictions that we test in the experiment. Section 3 describes the experimental design. Section 4 presents experimental results, while Section 5 is devoted to an alternative, information-based hypothesis. Section 6 concludes.

\section{A Model of Competitive Behavior}

Building on the work of Becker [1974] and Andreoni [1990], let us assume that individuals experience a "warm glow" from their altruistic actions. Consider a group of $N$ individuals who can convert, one-for-one, their endowment $z$ (in whole or in part) into some altruistic action $x$. Following Frank [1985] let us suppose that each individual also cares about her relative standing with respect to the other $N-1$ individuals. Let us suppose that an individual $i$ 's preferences over her altruistic action $x_{i}$, private surplus $y_{i}=z_{i}-x_{i}$, and rank $F_{i}$ can be represented by a utility function $U_{i}\left(x_{i}, y_{i}, F_{i}\right)$, where $U_{i 1} \geq 0, U_{i 2}>0, U_{i 3}>0$, and $U_{i}$ is continuous and quasi-concave. Following Hopkins and Kornienko [2004], let us further assume that for all individuals, taste for relative position is separable from tastes for

\footnotetext{
${ }^{4}$ Andreoni [1995] reports that, in a public goods experiment, giving information on an individual's rank in earnings induces less cooperative behavior relative to the standard public goods setup where information on relative earnings (rank) is not available. Moreover, he reports that subjects are even less cooperative when, in addition to seeing information on relative experimental earnings, subjects' payments are not based on their experimental earnings but are instead proportional to their relative rank. Bolton (1991) further reports that in alternating-offer bargaining game, the introduction of a payment scheme whereby subjects are paid according to their relative standing to other subjects in a group promotes self-regarding behavior.

${ }^{5}$ Barclay [2004] is an exception. He shows that competitive altruism may help to maintain cooperative behavior in public goods games.
} 
altruistic giving and money. ${ }^{6}$

We will consider three cases for the assignment of relative position. The first, benchmark case (denoted as $C$ ) is where relative position is assigned exogenously (e.g. randomly). That is, position of an individual $i$ is given by some function $F\left(t_{i}, t_{-i}\right)$ where $t_{i}$ is some variable beyond individual $i$ 's control ( $-i$ refers to all other individuals excluding $i)$. In this case, individual $i$ 's problem is:

$$
\max _{x_{i}, y_{i}} U_{i}^{C}\left(x_{i}, y_{i}, F\left(t_{i}, t_{-i}\right)\right) \text { subject to } x_{i}+y_{i}=z_{i}
$$

The second case we consider (denoted as $A$ ) is where relative position is assigned according to individuals' relative standing in altruistic action $x$. That is, the relative position of individual $i$ is given by some function $F\left(x_{i}, x_{-i}\right)$ which is non-decreasing in $x_{i}$. In this case, individual $i$ 's problem is:

$$
\max _{x_{i}, y_{i}} U_{i}^{A}\left(x_{i}, y_{i}, F\left(x_{i}, x_{-i}\right)\right) \text { subject to } x_{i}+y_{i}=z_{i}
$$

The third and final case (denoted as $S$ ) is where relative position is assigned according to individuals' relative standing in private surplus $y=z-x$. That is, the relative position of individual $i$ is given by some function $F\left(y_{i}, y_{-i}\right)$ which is non-decreasing in $y_{i}$. In this case, an individual $i$ 's problem is:

$$
\max _{x_{i}, y_{i}} U_{i}^{S}\left(x_{i}, y_{i}, F\left(y_{i}, y_{-i}\right)\right) \text { subject to } x_{i}+y_{i}=z_{i}
$$

While the problems above are of a strategic nature, we nevertheless are not interested in equilibrium outcomes. ${ }^{7}$ Instead, we are interested in understanding how individual best responses to others' choices vary across the three situations. This allows us to keep the analysis relatively simple while continuing to entertain the possibility of heterogeneity among subjects, e.g. that subjects differ in their taste for altruism as suggested by Andreoni and Samuelson [2003].

Proposition 1 Consider three mechanisms that assign relative position to individuals: a mechanism $C$ where relative position is exogenously determined, a mechanism $A$ where relative position is determined by the relative amount given and a mechanism $S$ where relative

\footnotetext{
${ }^{6}$ There is some anecdotal evidence that individuals with higher relative rankings, e.g. in terms of income, fame, feel obliged to give more. This however can be captured in our model by assuming that the individual's relative position outside of the laboratory (or current situation) may determine her propensity to give, however her taste for giving is separable from her ranking in inside the laboratory (or current situation).

${ }^{7}$ One can interpret our experimental design as a form of multi-prize charity auctions. For formal modelling of charity auctions, see Salmon and Isaac [2004] and Engers and McManus [2004].
} 
position is determined by the relative amount kept. For any profile of other people's giving, a given individual $i$ 's giving, $x_{i}$, can be ranked as follows:

$$
0 \leq \operatorname{argmax}_{x_{i}} U_{i}^{S} \leq \operatorname{argmax}_{x_{i}} U_{i}^{C} \leq \operatorname{argmax}_{x_{i}} U_{i}^{A} \leq z_{i}
$$

Proof: Let us begin by assuming that the rank function $F$ is continuously differentiable in the first argument (we will relax this assumption later). Consider first equation (1) corresponding to the situation where relative position is exogenously determined. Here, individual $i$ 's best response to other people's choices is given simply by a solution to the following Kuhn-Tucker condition:

$$
x_{i}\left(U_{i 1}-U_{i 2}\right)=0
$$

Given the separability of utility in rank, the solution is independent of others' choices and thus is equal to the individually optimal value of $x_{i}^{C}$. Obviously, if $U_{i 1}=0$ for all $x_{i}$, then we have a corner solution $x_{i}^{C}=0$.

Consider next equation (2) corresponding to the situation where relative position is determined by relative giving, $x$. In this case, individual $i$ 's best response to $x_{-i}$ is described by the following Kuhn-Tucker condition:

$$
x_{i}\left(U_{i 1}-U_{i 2}+U_{i 3} \frac{\partial F\left(x_{i}, x_{-i}\right)}{\partial x_{i}}\right)=0
$$

Here, the third term of the above equation expresses an incentive to give, as giving implies an extra return from rank. An individual faces a trade-off between the utility from the private surplus, $y_{i}$, and relative position, $F\left(x_{i}, x_{-i}\right)$. Here, even if $U_{i 1}=0$ for all $x_{i}$, we may not have the corner solution where the individual gives nothing. Consequently, for any profile of other people's giving $x_{-i}$, the best response $x_{i}^{A}$ is weakly greater than the individually optimal value $x_{i}^{C}$ (see Frank [1985b] and Hopkins and Kornienko [2004] for similar discussion).

Finally, consider equation (3) corresponding to the situation where relative position is determined by relative private surplus, $y$. In this case, individual $i$ 's best response to $y_{-i}$ is described by the following Kuhn-Tucker condition:

$$
x_{i}\left(U_{i 1}-U_{i 2}-U_{i 3} \frac{\partial F\left(y_{i}, y_{-i}\right)}{\partial y_{i}}\right)=0
$$

Here, the third term of the above equation expresses the disincentive to give, as giving implies a negative return from rank. Consequently, for any profile of other people's giving, $x_{-i}$, the best response, $x_{i}^{S}$, is weakly smaller than the individually optimal value, $x_{i}^{C}$. Moreover, if $U_{i 1}=0$ for all $x_{i}$, then we have a corner solution $x_{i}^{S}=0$.

Now let us relax the continuous differentiability assumption on the rank function $F$ and assume instead that $F$ has some discontinuities and "flat" spots. This does not change the best response $x_{i}^{C}$ for the benchmark $C$ case corresponding to the equation (1). 
Therefore, let us immediately move to the situation where relative position is determined by relative giving $x$, as described by equation (2). Note that for any profile of others' choices, $x_{-i}$, giving less than $x_{i}^{C}$ is strictly dominated in this case. That is, for any $\tilde{x}_{i}<x_{i}^{C}$,

$$
U_{i}\left(\tilde{x}_{i}, z_{i}-\tilde{x}_{i}, F\left(\tilde{x}_{i}, x_{-i}\right)\right) \leq U_{i}\left(x_{i}^{C}, z_{i}-x_{i}^{C}, F\left(x_{i}^{C}, x_{-i}\right)\right)
$$

To see why, consider some $\tilde{x}_{i}<x_{i}^{C}$ and, without loss of generality, suppose that $\tilde{x}_{i}$ is such that $F\left(\tilde{x}_{i}, x_{-i}\right)$ is constant in some vicinity of $\tilde{x}_{i}$. Then, $U_{i}\left(\tilde{x}_{i}, z_{i}-\tilde{x}_{i}, F\left(x_{i}^{C}, x_{-i}\right)\right)<$ $U_{i}\left(x_{i}^{C}, z_{i}-x_{i}^{C}, F\left(x_{i}^{C}, x_{-i}\right)\right)$ as, by separability in relative position, $x_{i}^{C}$ is individually optimal for any realization of $F$. Moreover, as $F$ is increasing in $x_{i}$, individual $i$ can further increase her relative position by increasing $x_{i}$. Second, if there are discrete jumps in the rank function $F$ in the vicinity of $x_{i}^{C}$, individual $i$ can increase $x_{i}$ by a small amount, $\epsilon$, and gain a discrete increase in $F$. Thus, when rank is determined by relative giving, giving less than $x_{i}^{C}$ is never optimal and, moreover, giving more is sometimes optimal.

A similar argument applies to the situation where relative position is determined by relative private surplus $y$, as described by equation (3). That is, for any profile of others' choices $y_{-i}$, giving more than $x_{i}^{C}$ is strictly dominated, and for some profiles $y_{-i}$, one can get a discrete improvement in relative position $F$ by lowering $x_{i}$. Thus, when rank is determined by relative private surplus, giving more than $x_{i}^{C}$ is never optimal and, moreover, giving less is sometimes optimal.

The rankings for individual giving, $x_{i}$, across the three information conditions as given in Proposition 1 provide us with the main hypothesis to be tested in our experiment. We next turn to a description of the experimental design.

\section{Experimental Design}

We employ a novel experimental design, which uses elements of both the one-shot dictator game design (Forsythe, Horowitz, Savin, and Sefton [1994]) and the sequential dictator game design (Cason and Mui [1998]). In the one-shot dictator game, each subject is paired randomly and anonymously with another subject. One member of each pair is designated as the "dictator", the other is designated as the "recipient," and a fixed amount of money is provisionally allocated to each pair. The dictator then unilaterally decides on (dictates) how this amount of money is to be divided between him/herself and the recipient or "match". The two players are then paid according to the dictator's allocation.

If a dictator's only goal is to maximize his/her earnings, then he/she should keep all of the money for her/himself, allocating zero the her/his match. However, there is now overwhelming evidence that many subjects give a substantial share of the money to the matched player. Various explanations for this finding have been offered all of them suggesting that subjects care not only about their monetary earnings but also about behaving in a socially appropri- 
ate way (see Forsythe, Horowitz, Savin, and Sefton [1994]; Hoffman, McCabe, Shachat, and Smith [1994]). In a sequential dictator game experiment conducted by Cason and Mui [1998], subjects make two dictator decisions and receive information about one other subject's firstround dictator allocation before making their second-round allocation decision. Contrary to their expectation, Cason and Mui [1998] report that the information about another subject's first-round allocation does not induce greater altruism by subjects in the second round of the experiment.

To explore the idea that giving behavior would respond to competitive urges, we modify Cason and Mui [1998]'s design as follows. First, to provide stronger social influence, subjects receive information about their relative standing with respect to all other dictators (subjects) in the room. Second, to create a tournament-like environment, this information is provided in terms of rank, with first (i.e., top) rank going to the player(s) who kept the most for themselves in the Selfish (S) treatment and to the player(s) who gave away the most (kept the least for themselves) in the Altruistic (A) treatment. In a third Control (C) treatment, players were informed that ranks were randomly assigned; therefore such rank assignments conveyed no information about the behavior of other players. Third, the social content of the game was reinforced by awarding a token to the subject(s) ranked 1st in every round of the three treatments. Finally, to allow subjects to adapt to their social surroundings (i.e. other subjects in the room), participants played 10 rounds of the dictator game with the same subjects.

Each experimental session involves 15 subjects who are randomly assigned to one of the three treatments ( 5 subjects per treatment). The treatments were conducted simultaneously in the three rooms. In each room, instructions were handed out and then read aloud. ${ }^{8}$ Players were informed that they were matched with another player in one of the other rooms and that this player would be the recipient of their dictator decision. The 5 dictators were then asked to simultaneously and privately allocate a fixed amount of money between themselves and their anonymous, fixed match for 10 rounds. While subjects were informed that they had an anonymous match in one of the other rooms $(i=1,2$ or 3$)$, in the "recipient" role, subjects in the dictator role were not informed (until the end of the experimental session) that they had also been randomly and anonymously assigned to be the recipient of the decision made by another dictator, in another room $(j \neq i)$, and that in this "recipient role" they would also receive the amount allocated to them by that dictator. ${ }^{9}$ Thus, each subject in a particular treatment (room) was matched with two other subjects (one each from the other two rooms) - her/his recipient in one room, and her/his dictator in the other, but was aware only of his/her match to a recipient. In all transactions and postings of information, subjects were identified by a private ID letter only.

\footnotetext{
${ }^{8}$ The interested reader can read/download the instructions used in all three treatments of the experiment at: http://www.pitt.edu/ jduffy/dictator/.

${ }^{9}$ We did not want subjects to think they should offer more as dictators because they were simultaneously serving in the recipient role.
} 
Each round consists of three steps. In the first step, subjects make decisions (on proposal forms) as to how they want to divide the $\$ 10$ that has been provisionally allocated to them they must specify dollar amounts for themselves and their match that add up to $\$ 10$. Next, an experimenter collects subjects' folded proposal forms in a basket and reviews and sorts these proposals according to the treatment-specific criterion. Finally the experimenter presents the ranked list of subjects' letter IDs on a blackboard according to the treatment-specific order; this ranking is observable to all subjects in the room. Note again that information on dollar amounts is not given; the information displayed on the blackboard consisted of a rankordered display of subjects letter IDs only. Subjects' letter IDs are private information; thus subjects were not identifiable to other subjects in the room or to the experimenter. Once subjects have had time to observe their ranks and record rank information on record sheets, a new round begins. Rank information from previous rounds was left on the blackboard. Subjects were specifically informed that their rank does not affect their cash earnings in any way and that, in addition to a show-up fee, the money they allocate to themselves in one of the 10 rounds, chosen at random at the end of the session, would be paid to them in cash. To focus attention on the competitive possibilities afforded by the rank information we provided, the subject(s) ranked number one in the round randomly selected for payment was also awarded a small button that said "\#1." In the event of a tie for top rank, all those ranked number one were awarded \#1 buttons. ${ }^{10}$ To preserve anonymity, the \#1 buttons were awarded only at the end of the session, privately and simultaneously with paying individual subjects according to their choice in the randomly selected round.

The treatment-specific criteria are as follows. In the Selfish $(\mathrm{S})$ treatment, the proposal forms were collected and sorted by the experimenter in descending order of the amounts subjects allocated to themselves. The person(s) who allocated the largest amount to him/herself relative to the rest of the subjects in the group, was (were) assigned 1st rank, the next largest amount was (were) awarded second rank, etc. ${ }^{11}$ Conversely, in the Altruistic (A) treatment, the proposal forms were sorted in descending order of the amounts subjects allocated to their match. The person(s) who allocated the largest amount relative to the rest of the subjects in the group was (were) assigned 1st rank, and so on. In the Control (C) treatment, after the proposal forms were collected, ranks were assigned according to the random order in which the proposal forms were drawn from a basket by the experimenter. ${ }^{12}$ Procedures for rank assignment in the three treatments were explained in the instructions and can be re-

\footnotetext{
${ }^{10}$ The value of the \#1 button was truly a token amount relative to the maximum amount that subjects could allocate to themselves $(\$ 10)$. The retail price of each button was $\$ 0.50$. A picture of the button can be viewed at http://www.pitt.edu/ jduffy/dictator/.

${ }^{11}$ In the event of ties, rank places were skipped. For instance, if two players tied for first rank, then there would be no second rank, and the next highest amount was awarded third rank, etc. The interested reader is referred to the data in Appendix Table A, which reports all experimental data including rankings of letter IDs as presented to subjects.

${ }^{12}$ We chose to assign spurious ranks in the Control treatment (rather than making no rank assigments) so as to minimize differences in the design of this treatment relative to the Altruistic and Selfish treatments. In the Control treatment, if the experimenter picked up two proposal forms at once, (a rare event) a tie rank was declared for those two subjects.
} 
garded as public information. In particular, subjects knew the meaning of rank information presented in the Selfish and Altruistic treatments and knew that rank information in the Control treatment was spurious.

Thus, each subject made their first decision in the absence of any socially relevant information. The subsequent nine decisions were made after all subjects learned how their previous allocations stood relative to all others in their group in the Selfish and Altruistic treatments, or among the randomly assigned ranks of the Control treatment. Since the highest amount kept is the lowest amount given away, the potential difference (if any) between the three treatments is entirely due to the competitive frame provided.

A total of 60 subjects participated in 4 sessions; no subject participated in more than 1 session. Each session consisted of 3 groups of 5 subjects each (one 5 -member group for each of the three treatments). The subjects were recruited from the undergraduate population of the University of Pittsburgh and had no prior experience with this experimental design. Subjects were guaranteed $\$ 10$ just for participating in the one-hour experiment, and were told that they "may earn an additional amount of money." 13 Subjects learned that they were the recipient of another dictator's decisions only following the last round of a session, and no subject was ever identified by name. Summarizing, subjects' earnings for this 1-hour experiment were the sum of three numbers: the $\$ 10$ participation payment, the amount they chose to allocate to themselves (out of \$10) in the one randomly chosen round, and the amount they received from another dictator (in another room) in one randomly chosen round.

\section{Experimental Results}

All of the raw data from our experimental sessions is shown in Appendix Table A. In the following sections we report on our analysis of this data. ${ }^{14}$

\footnotetext{
${ }^{13}$ The $\$ 10$ participation payment was intended to provide subjects with sufficient compensation for their time spent in the experiment (one-hour). We were careful to avoid suggesting how much subjects could earn in addition to the participation payment to avoid creation of norms regarding socially acceptable amounts of giving.

${ }^{14}$ The careful reader will note that the individual data on giving in Appendix Table A also includes the gender of each subject. While we found some gender differences in giving, these differences are not uniform across treatments - that is, no gender was more "generous" than the other in all treatments. An analysis of gender differences is available by request.
} 


\subsection{Overall Behavior}

We begin our analysis of the experimental findings with some descriptive statistics on the overall amounts given away by dictators across the three treatments. As Table 1 reveals, the mean, total and proportional levels of giving across all rounds of all sessions of the three treatments appear to be consistent with our main hypothesis, as stated in Proposition 1; the mean (total or proportional) amount given is highest in the Altruistic treatment and lowest in the Selfish treatment. ${ }^{15}$

\begin{tabular}{|l|c|c|c|}
\hline Treatment & Selfish (S) & Altruistic (A) & Control (C) \\
\hline Number of Observations & $4 \times 5 \times 10=200$ & $4 \times 5 \times 10=200$ & $4 \times 5 \times 10=200$ \\
Overall Mean Giving (St.Err.) & $1.21(1.74)$ & $2.88(2.94)$ & $1.6(2.09)$ \\
Total Amount Given & 241.68 & 576.68 & 320 \\
As Proportion of Total Funds & $12.1 \%$ & $28.8 \%$ & $16.0 \%$ \\
\hline
\end{tabular}

Table 1: Descriptive statistics for all treatments.

The frequency and cumulative distributions of individual giving for all 200 observations of each treatment are presented in Figure 1.

[Figures 1-2 here.]

As Table 1 and Figure 1 suggest, the amounts given in the Altruistic treatment appear to be much larger than in either the Selfish or the Control treatments. Indeed, as Figure 2 demonstrates, there are more "other-regarding" subjects giving $\$ 5$ or more per period in the Altruistic treatment than in either the Selfish or the Control treatments, and there are more "self-regarding" subjects, giving $\$ 1$ and less per period in the Selfish treatment than in the Altruistic treatment. Starting from round 5, the number of self-regarding subjects per round is greater in the Selfish treatment than in the Control one.

While the differences in giving across the three treatments appears to be in accordance with our predictions, whether these differences are statistically significant or not depends on

\footnotetext{
${ }^{15}$ The overall mean giving in our experiment is different from that reported in previous dictator experiments. For example, Forsythe, Horowitz, Savin, and Sefton [1994] report that in the "\$10 pies and pay" experiments, the average offer is $\$ 2.33(23.3 \%)$, and in the two " $\$ 5$ pies and pay" experiments the average offers are $\$ 1.07(21.4 \%)$ and $\$ 1.5(30 \%)$. Cason and Mui [1998] report that for the $\$ 40$ pie subjects divided in each of the two periods of their experiment, the average offers in the "Relevant Information" and "Irrelevant Information" treatments are, respectively, $\$ 8.9(22.3 \%)$ and $\$ 12.9(32.3 \%)$ in the first choice and $\$ 9.3(23.3 \%)$ and $\$ 9.4(23.5 \%)$ in the second choice. That is, in the Selfish and the Control treatments, subjects made more selfish choices than has been previously observed. Interestingly, the amounts given in our Altruistic treatment are more selfish than in some of these prior experiments. We discuss possible reasons for this in Sections 4.3 and 5 .
} 
whether we exclude the first round, in which individuals did not have information on their relative rank.

Finding 1 Using data for all rounds, the Altruistic treatment generates a significantly higher level of giving than the Selfish or the Control treatments do, while the difference in giving levels between the Selfish and the Control treatments are statistically insignificant.

Support for this finding is based on an analysis of the four session-level means for each treatment. Using these means, a nonparametric, robust rank order test reveals that the Altruistic frame generates significantly larger giving from that observed in either the Selfish or the Control treatments ( $\grave{U}_{4,4}=2.502, p=0.05$ for both comparisons), while the difference in mean giving between the Selfish and the Control is statistically insignificant $\left(\grave{U}_{4,4}=0.834\right)$.

\begin{tabular}{|c|c|c|c|}
\hline Treatment & Info & \# Observations & Mean Giving (St.Err.) \\
\hline Selfish (S) & Round 1 & 20 & $2.58(2.17)$ \\
Selfish (S) & Rounds 2-10 & 180 & $1.06(1.63)$ \\
\hline Altruistic (A) & Round 1 & 20 & $3.43(2.36)$ \\
Altruistic (A) & Rounds 2-10 & 180 & $2.82(3.01)$ \\
\hline Control (C) & Round 1 & 20 & $1.75(2.17)$ \\
Control (C) & Rounds 2-10 & 180 & $1.58(2.09)$ \\
\hline
\end{tabular}

Table 2: Descriptive Statistics for Round 1 and Rounds 2-10 for all subjects.

We next consider initial (Round 1) and subsequent (Rounds 2-10) allocations separately. Ideally, there would be no significant difference in round 1 behavior across the three treatments as subjects have no information about their relative performance in this initial round. However, in the Selfish and Altruistic treatments, subjects may respond immediately to the competitive urges induced by our experimental design, which may lead to first round differences (instructions for all rounds are read in advance of the play of the first round). In subsequent rounds (2-10), where information on relative performance is available in the Altruistic and Selfish treatments and spurious rankings are provided in the Control treatment, the importance of the competitive urge can be more completely assessed.

\begin{tabular}{|l|c|c|c|}
\hline Pair of Treatments & Selfish vs. Altruistic & Altruistic vs. Control & Selfish vs. Control \\
\hline Round 1 & $D_{20,20}=0.3$ & $D_{20,20}=0.4$ & $D_{20,20}=0.3$ \\
significance (1-tail) & $p>0.10$ & $p=.05$ & $p>0.10$ \\
\hline Rounds 2-10 & $\chi^{2}=48.40$ & $\chi^{2}=22.5$ & $\chi^{2}=6.40$ \\
significance (1-tail) & $p=0.001$ & $p=0.001$ & $p=0.05$ \\
\hline
\end{tabular}

Table 3: Kolmogorov-Smirnov test statistics from pairwise comparisons of giving. 
Finding 2 Initial, first round giving by all subjects in the Altruistic treatment is significantly higher than in the Control treatment, but there is no significant difference in first round giving between the Altruistic and Selfish treatments and only a marginal difference in first round giving between the Selfish and Control treatments.

Support for this finding and the next one is found in Table 3, which reports results from Kolmogorov-Smirnoff tests (see also Figure 3). We conclude from these test results that the ideal outcome of no significant differences in first round behavior is realized in two of three pairwise comparisons. We next consider allocations over rounds 2-10.

Finding 3 In the second through tenth rounds, giving in the Altruistic treatment is significantly higher than in either the Control or Selfish treatments. Further, giving in the Selfish treatment is significantly lower than in either the Altruistic or Control treatments.

That is, pairwise comparisons using non-parametric Kolmogorov-Smirnoff tests, as reported in Table 3 reveal that the distributions of giving over rounds 2-10 are significantly different at the 5 percent level in all pairwise comparisons of the three treatments ${ }^{16}$ (see also Figure 3). We conclude from Findings 2-3 that the lack of a significant difference in giving levels between the Selfish and Control treatments over all 10 rounds (Finding 1) is owing to the amounts given in the first rounds of these two treatments.

[Figure 3 here.]

We next consider aggregate behavior over time, in particular, whether there is evidence that subjects were converging to the unique, subgame perfect equilibrium where they keep all of the endowment for themselves (giving nothing to their match), regardless of the treatment.

Figure 4 shows the average amounts given in each round of the four sessions of each of the three treatments. In the Selfish treatment and to a lesser extent in the Altruistic treament, we see evidence for a a decreasing trend in the amount given as subjects receive feedback/gain experience but we see no clear trend in giving over time in the four sessions of the Control treatment.

[Figure 4 here.]

\footnotetext{
${ }^{16}$ This result (and subsequent results using the Kolmogorov-Smirnov test) hold regardless of whether we look at session-level averages or, as in Table 3, we use all data (all subjects all sessions) for rounds $2-10$ from a given treatment.
} 
To better address the convergence question, we use a simple regression model that has been used to examine convergence questions in several other studies (e.g. by Noussair et al. [1995]), given by:

$$
x_{k t}=\sum_{k=1}^{4} \beta_{1 k}\left(\frac{D_{k}}{t}\right)+\beta_{2}\left(\frac{t-1}{t}\right)+\epsilon_{k t} .
$$

Here, $x_{k t}$ is the average amount given in period $t$ by the 5 players in session $k=1,2,3,4$ of a single treatment; alternatively, one can think of $x_{k t}$ as the average deviation from the equilibrium prediction of $0 . D_{k}$ is a session dummy variable equal to 1 for observations associated with session $k, 0$ otherwise and $\epsilon_{k}$ denotes an session-specific error term. The dummy variables have full weight 1 in the initial period $t=1$, but asymptote to zero as $t \rightarrow \infty$. By contrast, the variable $(t-1) / t$ has value zero in the initial period and asymptotes to 1 as $t \rightarrow \infty$. Hence, the coefficients $\beta_{1 k}$ can be interpreted as initial average amounts given by dictators in session $k$, while the coefficient $\beta_{2}$ can be interpreted as the average amount given in the limit across all 4 sessions; the game-theoretic prediction is that $\beta_{2}$ is 0 . Evidence of convergence toward this prediction would require that the coefficients $\beta_{1}$ are all greater than $\beta_{2}$.

\begin{tabular}{|l|cccc|c|cc|c|}
\hline Treatment & $\beta_{11}$ & $\beta_{12}$ & $\beta_{13}$ & $\beta_{14}$ & $\beta_{2}$ & Log L & Wald chi $^{2}$ & Nobs \\
\hline Selfish & 2.204 & 1.044 & 3.909 & 3.386 & 0.729 & -19.326 & 238.63 & 40 \\
& $(0.586)$ & $(0.316)$ & $(0.374)$ & $(0.551)$ & $(0.146)$ & & $p=0.000$ & \\
\hline Altruistic & 2.935 & 2.683 & 5.220 & 4.541 & 2.970 & -32.106 & 870.67 & 40 \\
& $(0.635)$ & $(0.673)$ & $(0.871)$ & $(0.330)$ & $(0.163)$ & & $p=0.000$ & \\
\hline Control & 0.850 & 0.107 & 3.344 & 2.582 & 1.568 & -35.458 & 204.51 & 40 \\
& $(0.482)$ & $(0.665)$ & $(0.722)$ & $(0.435)$ & $(0.166)$ & & $p=0.000$ & \\
\hline
\end{tabular}

Note: Estimates obtained using a generalized least-squares estimator that allows for first-order serially correlated disturbances and corrects standard errors for heteroskedasticity. "Log L" = Log Likelihood.

Table 4: Regression coefficient estimates from estimation of equation (8), all subjects

The regression results, as shown in Table 4, indicate that the coefficient estimates are almost always significantly different from zero. The $\beta_{2}$ coefficient estimates provide further evidence of differences between the three treatments consistent with Proposition 1 and Finding 3. In particular, subjects in the Selfish treatment are closest to converging to the equilibrium prediction of giving zero to their match; the coefficient estimate on $\beta_{2}$ is 0.729 . Subjects in the Altruistic treatment are the furthest from the equilibrium prediction with a $\beta_{2}$ coefficient of 2.970 , while subjects in the Control treatment have a $\beta_{2}$ coefficient that lies in between these values. Notice, further that for the Altruistic and Control treatments, there is not strong evidence favoring convergence to the equilibrium prediction, as the coefficient estimates associated with the dummy variables, $\beta_{1 k}$ are sometimes smaller than the $\beta_{2}$ coefficients for the same treatment. By contrast, the strong evidence in support of convergence in the Selfish frame may reflect the alignment between selfish interest and competitive 
pressures in that treatment, which is not present in the other two treatments.

\subsection{Heterogeneity Among Subjects}

We next seek to understand individual subject behavior. We first notice that, as in Cason and Mui [1998], some subjects never changed their choices - that is, they chose the same allocation for all 10 rounds. We label those who never changed their allocation decision from the one they made in the very first round as Resolute subjects, and we label those who changed their allocation decision at least once over the 10 rounds played as Non-Resolute subjects. Our first finding is that the proportion of Resolute subjects differs across the three treatments.

Finding 4 More subjects change their allocation decisions at least once when presented with some socially relevant information (in the Selfish and the Altruistic treatments) than when such information is absent (in the Control treatment).

\begin{tabular}{|l|c|c|c|}
\hline Treatment & Selfish (S) & Altruistic (A) & Control (C) \\
\hline Number of Non-Resolute Subjects & $16(80 \%)$ & $14(70 \%)$ & $10(50 \%)$ \\
Average Giving & 1.20 & 3.40 & 2.60 \\
Total Giving & 191.68 & 476.68 & 260.00 \\
Share of Total Giving & $79.3 \%$ & $82.7 \%$ & $81.3 \%$ \\
\hline Number of Resolute Subjects & $4(20 \%)$ & $6(30 \%)$ & $10(50 \%)$ \\
of which giving $\$ 0$ & $3(15 \%)$ & $4(20 \%)$ & $8(40 \%)$ \\
$-"$ - giving $\$ 1$ & $0(0 \%)$ & $0(0 \%)$ & $1(5 \%)$ \\
$-"$ - giving $\$ 5$ & $1(5 \%)$ & $2(10 \%)$ & $1(5 \%)$ \\
Average Giving & 1.25 & 1.67 & 0.60 \\
Total Amount Given & 50 & 100 & 60 \\
Share of Total Givings & $20.7 \%$ & $17.3 \%$ & $18.7 \%$ \\
\hline
\end{tabular}

Table 5: Statistics for Resolute subjects (those who never changed their allocation) and Non-Resolute subjects (those who changed their allocation at least once). Percentages in the parentheses represent the proportions of all subjects in a given treatment.

In other words, a lower proportion of subjects are Resolute when some kind of social context is present (as in the Selfish and the Altruistic treatments) than when social context is absent (as in the Control treatments). The data supporting this finding is presented in Table 5. As the data shows, in the social context treatments, there is an extensive adjustment process going on; this same process is strikingly absent in the Control treatment. As we will 
show later, this adjustment process responds in a predictable fashion to the given social frame. ${ }^{17}$

Importantly, in the Altruistic and the Control treatments, Resolute subjects, in the aggregate, gave significantly less than Non-Resolute subjects (robust rank order test $\grave{U}_{6,14}=$ 8.617, $p=0.00003$ for the Altruistic and $\grave{U}_{10,10}=3.908, p=0.01$ for the Control treatments), while there is no significant difference between aggregate allocations made by the two types of subjects in the Selfish treatment (robust rank order test $\grave{U}_{4,16}=1.12022, p=0.1314$ ). That is, those subjects who are Resolute tend to generate more selfish behavior in the aggregate. Also, in the aggregate, the Selfish frame induces adjustments by Non-Resolute subjects in the direction of Resolute subjects.

In the remainder of this section, we focus on the behavior of Non-Resolute subjects. As we show, it is these subjects who respond to the social frame, and thus behave more selfishly when the Selfish frame is present, and more altruistically when the Altruistic frame is present. Also, these subjects' choices in the first round are different from their choices in the subsequent nine rounds, where they get additional information from the ranking of other participant's choices.

\begin{tabular}{|l|c|c|c|}
\hline Treatment & Selfish (S) & Altruistic (A) & Control (C) \\
\hline Round 1 - Number of Observations & 16 & 14 & 10 \\
Round 1 - Mean Giving (St.Err.) & $2.91(4.13)$ & $4.18(3.52)$ & $2.90(4.54)$ \\
\hline \hline Rounds 2-10 - Number of Observations & 144 & 126 & 90 \\
Rounds 2-10 - Mean Giving (St.Err.) & $1.01(2.14)$ & $3.32(9.71)$ & $2.57(4.57)$ \\
\hline
\end{tabular}

Table 6: Descriptive statistics of Non-Resolute subjects' giving in the 1st Round and the subsequent Rounds 2-10.

[Figure 5 here.]

Descriptive statistics for the behavior of Non-Resolute subjects are presented in Table 6 . The cumulative distributions of giving by Non-Resolute subjects in the first and subsequent nine rounds are presented in Figure 5. Consider first the choices of Non-Resolute subjects in round 1. As one can see from Table 6 and Figure 5, the first-round average giving in the Altruistic treatment is higher than in both the Selfish and the Control treatments. Indeed, the distribution of choices in the Altruistic treatment first-order stochastically dominates the distribution of choices in the Control treatment. However, this difference turns out to

\footnotetext{
${ }^{17}$ The proportion of Resolute subjects in the Control treatment (10 out of 20 ) is similar to what Cason and Mui [1998] found (9 out of 20) in their experiment. However, Cason and Mui [1998] also report that only 16 out of 40 subjects changed their decision when social information was present, while we find that a larger fraction of subjects (30 out of 40) changed their decisions at least once when social context was present.
} 
be statistically insignificant. That is, the competitive altruistic frame appears to have an initial beneficial effect, but this happens only by chance - because of the initial (random) composition of subjects. We can summarize this finding as follows.

Finding 5 Among Non-Resolute subjects, there is no significant difference in the initial giving generated by the three frames, with the Altruistic social frame generating (insignificantly) higher initial average giving than the Selfish or the Control frames.

\begin{tabular}{|l|c|c|c|}
\hline Pair of Treatments & Selfish vs. Altruistic & Altruistic vs. Control & Selfish vs. Control \\
\hline Round 1 & $D_{16,14}=0.4107$ & $D_{14,10}=0.3857$ & $D_{16,10}=0.1375$ \\
significance (1-tail) & $p=.10$ & $p>.10$ & $p>.10$ \\
\hline Rounds 2-10 & $\chi^{2}=56.715$ & $\chi^{2}=24.005$ & $\chi^{2}=24.004$ \\
significance (1-tail) & $p=.001$ & $p=.001$ & $p=.001$ \\
\hline
\end{tabular}

Table 7: Kolmogorov-Smirnov test statistics from pairwise comparisons of giving among Non-Resolute subjects only.

On the contrary, there is a marked difference in the behavior of Non-Resolute subjects in the subsequent nine rounds across the three treatments. As Figure 5 demonstrates, the distributions of the Altruistic and the Control choices first-order stochastically dominate the distribution of the Selfish choices. In other words, the Selfish frame induces an adjustment of choices towards selfish behavior. In comparing the Altruistic and the Control choices, notice that, while there is a clear tendency for the Altruistic choices toward greater generosity, there is also a clear increase in the dispersion of the choices (which we will explore further in the Section 4.3. Moreover, as Table 7 shows, all the differences in these choices are statistically significant. In other words, the average behavior of subjects in the second through tenth rounds confirms the hypothesis that competition may stimulate giving, and we summarize this finding as follows.

Finding 6 The behavior of Non-Resolute subjects in the second through tenth rounds results in the highest average giving in the Altruistic treatment, followed by the Control treatment, and it results in the lowest average giving in the Selfish treatment.

[Figure 6 here.]

We will now turn to the within-treatment analysis of the adjustments of Non-Resolute subjects' decisions, that is, how their decisions in the second through tenth rounds stand relative to their decisions in the first round within each treatment. From Table 6 and Figure 5 , the first-round average giving in all three treatments is higher than the average giving in 
the subsequent nine rounds. The distributions of giving within each treatment are shown in Figure 6. As the latter figure reveals, the adjustment of choices by Non-Resolute subjects after the first round follows a different pattern within each treatment. Specifically, subjects exhibit a marked increase in self-regarding behavior within the Selfish frame, while their choices become both more selfish and more dispersed within the Altruistic frame. On the other hand, there seems to be hardly any difference in the distributions of choices between the first and subsequent rounds within the Control frame. This leads us to the following finding.

Finding 7 Giving by Non-Resolute subjects in the second through tenth rounds relative to the first round is significantly lower in the Selfish treatment, marginally lower in the Altruistic treatment, and insignificantly lower in the Control treatment.

This finding is supported by a Kolmogorov-Smirnoff (one-tailed) test of within-treatment differences between the distributions of giving in Round 1 and Rounds 2-10. For the Selfish treatment, $\chi^{2}=12.84(p=.01)$, for the Altruistic treatment, $\chi^{2}=5.60(p=.1)$, for the Control treatment, $\chi^{2}=0.54(p=.8)$.

These last findings give us some interesting insights into competitive altruism among NonResolute subjects. In the first round, the Altruistic frame does not generate significantly more giving over and above that generated by the other two frames. Moreover, regardless of the frame, the average amount given tends to decline as subjects make adjustments to their choices. Yet, despite the fact that, the Altruistic frame fails to generate further increases in aggregate giving, that frame is nevertheless successful at counteracting or reducing selfregarding behavior. Over rounds 2-10, the choices of those in the Selfish treatment became even more self-regarding, while the choices of those in the Altruistic treatment also became somewhat more self-regarding - "catching up" with the choices made by subjects in the Control treatment, where choices did not change significantly. In other words, the rate at which overall giving declines varies across the three treatments - with the fastest rate being observed in the Selfish treatment, followed by the Altruistic treatment and finally, almost no change in the Control treatment.

Further evidence in support of these conclusions can be found by re-examining the convergence model (8), but restricting the data to consist of average amounts given in each session by Non-Resolute subjects only. The results from this estimation exercises are reported in Table 8.

Here we see very strong evidence of convergence to the equilibrium prediction in the Selfish treatment; the estimate of $\beta_{2}$ is positive but not significantly different from zero, and lies well below the $\beta_{1 k}$ estimates for that treatment. We also see stronger evidence of convergence in the Altruistic treatment than we saw when the Resolute subjects were also included (c.f. Table 4); the estimates of $\beta_{1 k}$ all lie above the estimate of $\beta_{2}$ for the Altruistic 


\begin{tabular}{|l|cccc|c|cc|c|}
\hline Treatment & $\beta_{11}$ & $\beta_{12}$ & $\beta_{13}$ & $\beta_{14}$ & $\beta_{2}$ & Log L & Wald chi & Nobs \\
\hline Selfish & 2.958 & 1.698 & 3.285 & 3.340 & 0.199 & -23.763 & 182.82 & 40 \\
& $(0.460)$ & $(0.273)$ & $(0.428)$ & $(0.732)$ & $(0.122)$ & & $p=0.000$ & \\
\hline Altruistic & 5.151 & 3.073 & 4.544 & 4.331 & 2.613 & -45.358 & 569.74 & 40 \\
& $(1.610)$ & $(0.779)$ & $(1.216)$ & $(0.396)$ & $(0.193)$ & & $p=0.000$ & \\
\hline Control & 3.890 & 1.666 & 2.417 & 4.446 & 2.028 & -55.222 & 306.04 & 40 \\
& $(1.004)$ & $(0.537)$ & $(0.763)$ & $(0.859)$ & $(0.195)$ & & $p=0.000$ & \\
\hline
\end{tabular}

Note: Estimates obtained using a generalized least-squares estimator that allows for first-order serially correlated disturbances and corrects standard errors for heteroskedasticity. "Log L" = Log Likelihood.

Table 8: Regression coefficient estimates from estimation of equation (8), Non-Resolute subjects only.

treatment. Finally, evidence for convergence in the Control treatment remains weak as when the Resolute subjects were included. ${ }^{18}$

As Table A in the Appendix demonstrates, the within-session initial allocation appears to play an important role in these findings. Results from the first two sessions of the Selfish treatment (S1 and S2) as well as from the second session of the Altruistic treatment (A2) suggest that when at least two out of five subjects choose to give zero in the first round, by the final round, four out of five subjects are choosing to give zero. This finding highlights the role played by Resolute subjects in the observed hysteresis, as those subjects who choose to give zero in the first round also had a tendency to make no changes in their allocations in all subsequent rounds. Furthermore, as Table B in the Appendix shows, there is substantial individual heterogeneity in the adjustment of choices to rank. We explore this adjustment process in detail in the next subsection.

\subsection{Heterogeneity Among Non-Resolute Subjects}

In the previous subsection we analyzed the behavior of Non-Resolute subjects across treatments. Yet, the puzzle remains: why does overall giving by Non-Resolute subjects in the Altruistic treatment decline over time? As we show in this subsection, the answer to this question is that there is heterogeneity among the Non-Resolute subjects as well. Some of these subjects in the Altruistic treatment do respond to the competitive pressures but others do not. To identify whether a subject is responsive to the competitive pressures, or whether her behavior is driven by some other motives, we look at how subjects adjusted their allocation in response to information on their rank, again focusing exclusively on those subjects

\footnotetext{
${ }^{18}$ For each Control session, we also ran the regression model using individual subject data (as there is no group interaction in that treatment), with a dummy term for each subject, but we did not find any stronger evidence in favor of convergence with this model specification.
} 
classified as Non-Resolute.

There are two issues that arise in considering how Non-Resolute subjects adjust their allocations in response to rank information. First, an examination of changes in the dollar amount of subjects' allocations in response to rank information (a cardinal measure) is potentially misleading, as small changes in dollar amounts may or may not lead to large changes in rank. Therefore, we look instead at the directional adjustment of subjects' giving in response to rank information (an ordinal measure). Another important issue concerns the possibility of ties for the same rank, which occurs frequently in the experimental data. For example, as can be seen in Table A of the appendix, beginning with round 7 of Session $S 1$ there is only one rank - rank 1 . On the other hand, in Session $S 2$ in $60 \%$ of the rounds there were only two ranks - rank 1 and rank 5, while in the Session $A 2$ there was typically just two ranks - rank 1 and rank 3 in Round 1, and rank 1 and rank 2 starting in round 3 . In most other sessions and rounds there were more than two ranks. To simplify the analysis of adjustment to ranks, we define the "top" rank as Rank 1, the lowest rank in a round as "bottom" rank, and the "middle" rank as a rank which is neither "top" nor "bottom".

We now turn to an analysis of how subjects changed their allocations in response to their rank in the previous round.

\begin{tabular}{|l|c||c|c|c||c|}
\hline Treatment & Rank & Increase $(\Uparrow)$ & No Change $(\equiv)$ & Decrease $(\Downarrow)$ & Total for Rank \\
\hline Selfish (S) & Top & 18 & $42(+27)$ & 1 & $61(+27)$ \\
& Middle & 11 & $12(+0)$ & 28 & $51(+0)$ \\
& Bottom & 1 & $6(+9)$ & 25 & $32(+9)$ \\
\hline & Total & 30 & $60(+36)$ & 54 & $144(+36)$ \\
\hline \hline Altruistic (A) & Top & 3 & $19(+1)$ & 21 & $43(+1)$ \\
& Middle & 22 & $0(+16)$ & 13 & $35(+16)$ \\
& Bottom & 8 & $38(+37)$ & 2 & $48(+37)$ \\
\hline & Total & 33 & $57(+54)$ & 36 & $126(+54)$ \\
\hline \hline Control (C) & Top & 8 & $4(+18)$ & 6 & $18(+18)$ \\
& Middle & 21 & $17(+47)$ & 23 & $61(+47)$ \\
& Bottom & 2 & $2(+25)$ & 7 & $11(+25)$ \\
\hline & Total: & 31 & $23(+90)$ & 36 & $90(+90)$ \\
\hline
\end{tabular}

Table 9: Non-Resolute subjects' changes in their giving in response to their previous-round ranks across treatments. (Numbers in parentheses are for the decisions of the Resolute subjects).

Finding 8 Rank does not affect the directional adjustment of choices by Non-Resolute subjects when it is randomly assigned in the Control treatment, but rank does affect the adjustment of choices by Non-Resolute subjects when it is non-randomly assigned (informative) as in the Selfish and the Altruistic treatments. 
Support for this finding is presented in Table 9, as well as in Table A in the Appendix. The impact of previous-round rank on the change in a Non-Resolute subject's allocation relative to the previous round is not significant in the Control treatment according to a chi-square test $\left(\chi^{2}=3.62, d f=4, p=0.5\right)$, but it is significant in the Selfish treatment $\left(\chi^{2}=65.03, d f=4, p=0.001\right)$ and in the Altruistic treatment $\left(\chi^{2}=70.84, d f=4, p=\right.$ 0.001). That is, directional adjustment by Non-Resolute subjects in the Control treatment is entirely due to a noisy second-thought process. This finding stands in contrast to the treatments with Selfish and Altruistic competitive frames, where the behavior of others in the group is important. In the remainder of this section, we therefore choose to focus further on how subjects in the Selfish and Altruistic treatments changed their allocations in response to information on rank (in light of the finding above, we ignore the directional adjustment of subjects in the Control treatment).

We hypothesize that the way subjects respond to rank information in the Selfish and Altruistic treatments depends on their individual "type." For some subjects, information on other subjects' behavior (ranks) matters for competitive reasons while for other subjects it may matter for some other reason - for example, it may be an important source of information, a hypothesis we consider later in Section 5). Some subjects, as we shall see, may not be easily classified as a single type.

We hypothesize that, among Non-Resolute subjects, there exist three possible types - the "Competitive" (subsequently labeled with a $\star$ ), "Conformist" (labeled with $\odot$ ) and "Pecuniary" (labels with a \$). The Competitive subjects, i.e., those who are responsive to competitive pressures, adjust their giving in the direction of the top rank - unless they have attained the top rank. That is, for all ranks except the top, the Competitive subjects in the Selfish treatment decrease their giving and in the Altruistic treatment they increase their giving. We do not have any prediction for the behavior of the Competitive subjects who have achieved the top rank. Those subjects could change their allocations further in the direction of the top rank for strategic reasons (e.g. to break a tie), or they could keep their allocation unchanged until challenged by another subject, or because of the zero lower bound on giving, in the Selfish treatment. A further possibility is that top ranked players might actually reduce their allocations from the levels that secured them top rank (in the previous period) so as to "shade" their bids, and avoid a "winner's curse."

The second type of Non-Resolute subject, the Conformist, prefers to be in the "middle". This type chooses to worsen her ranking when at the top (thus increasing her giving in the Selfish treatment and decreasing her giving in the Altruistic treatment), and chooses to improve her ranking when at the bottom (thus decreasing her giving in the Selfish treatment and increasing her giving in the Altruistic treatment), and does not change for the middle ranks.

The third and final type of Non-Resolute subjects are those with strictly Pecuniary concerns, regardless of the treatment. These subjects decrease their giving in response to 
all possible realizations of ranks, unless they possess top rank in the Selfish treatment or bottom rank in the Altruistic treatment, in which case further reductions in allocations may be unnecessary (or impossible). The predicted directional adjustments to previous round rank for the three types of Non-Resolute players are presented in Table 10.

A table showing the number of times that individual subjects made increases, decreases or no change in their allocations as a function of their previous period rank is given in Table $\mathrm{B}$ of the Appendix.

\begin{tabular}{|c|c|c|c|}
\hline Subject's Type & Rank & Adjustment in Selfish & Adjustment in Altruistic \\
\hline Competitive $(\star)$ & Top & $\Downarrow$ or $\equiv$ or $\Uparrow$ & $\Uparrow$ or $\equiv$ or $\Downarrow$ \\
& Middle & $\Downarrow$ & $\Uparrow$ \\
& Bottom & $\Downarrow$ & $\Uparrow$ \\
\hline Conformist (๑) & Top & $\Uparrow$ & $\Downarrow$ \\
& Middle & $\equiv$ & $\Uparrow$ \\
& Bottom & $\Downarrow$ & $\Downarrow$ \\
\hline Pecuniary (\$) & Top & $\Downarrow$ or $\equiv$ & $\Downarrow$ \\
& Middle & $\Downarrow$ & $\Downarrow$ or $\equiv$ \\
\hline
\end{tabular}

Table 10: Three possible types of Non-Resolute subjects and their possible directional adjustment to previous-period rank. ( $\Uparrow$ represents an increase in giving, $\Downarrow$ represents a decrease in giving, 三 represents no change.)

Notice that the directional adjustment processes for the Competitive and Conformist subjects in the Selfish treatment are the mirror images of those for the Altruistic treatment but for the Pecuniary type, the adjustment processes are the same for both treatments. So, in the absence of the Pecuniary subjects, and in the case of an equal distribution of the Competitive and Conformist subjects across the two treatments, the directional adjustment process in the Selfish treatment would be a mirror image of those found in the Altruistic treatment. However, as the next finding summarizes, there is no support for the hypothesis that adjustment dynamics in response to rank information in the Altruistic treatment are the mirror image (opposite) of those in the Selfish treatment.

Finding 9 Among Non-Resolute subjects, there is a significant difference in the directional adjustment process in the Selfish and the Altruistic treatments.

That is, the adjustment process in the Altruistic treatment and the mirror image of the adjustment process in the Selfish treatment are significantly different. Support for this finding is found in Table 9 using a Chi-squared test of the null hypothesis that the adjustments in the Altruistic case are the opposite of those in the Selfish treatment $\left(\chi^{2}=54.19, d f=\right.$ 
$8, p=0.001$ ). The rejection of this null hypothesis suggests that competitive (or conformist) behavior alone cannot explain what is going on in the two treatments. As we shall see, the presence of Pecuniary types in both treatments plays an important role.

In Appendix Table C, we use the information in Appendix Table B in an effort to classify individual subjects in the Selfish and Altruistic treatments into one of the three types we have identified above. We adopt an arbitrary but intuitive and informative classification scheme. In particular, we count the number of rounds (out of 9) for which a subject's adjustment behavior is consistent with the predictions given in Table 10. If a type classification predicts adjustments of the subject in $K=6(2 / 3)$ or more rounds, we regard that classification as "high" or "strong" and label the count (number of times the strategy correctly predicts) $K_{h} \geq 6$. A lesser or "weak" classification predicts behavior in just 5 or fewer rounds; its count is labeled $K_{l} \leq 5$. The subject is classifiable according to its high type(s) provided that $\min _{h}\left[K_{h}\right]-\max _{l}\left[K_{l}\right] \geq 2$. Notice that this criterion allows for more than one classification for each subject (if there is more than one $K_{h}$ ). If the latter inequality is not satisfied, or if there are no high classifications, the subject is considered "Unclassified" (and labeled as ?).

Notice in Appendix Table $\mathrm{C}$ that there is no ambiguity in our classification of subjects in the Altruistic session and further, that there are no subjects who fall into the Conformist category. However, the classification of subjects in the Selfish treatment is not so clear-cut. First, there is a significant overlap between Competitive and Pecuniary subjects in the Selfish treatment, so they are lumped in one "Competitive/Pecuniary" category together. Second, there is only one subject classified to be a Conformist (Subject 2 in session S3). Third, the rest of the subjects in the Selfish treatment do not satisfy the above classification criterion, so they are Unclassified (S?). In the analysis that follows, we will include the only Conformist subject into the Unclassified category.

For each directional adjustment type, Table D in the Appendix presents initial (Round 1) and subsequent (Rounds 2-10) giving as well as average 10-round giving for each subject. Notice that initial choices are not good predictors of subjects' subsequent behavior, but there seems to be a systematic relationship between the way people change their decisions in response to their relative position and their levels of giving.

The support for the subsequent findings can be found by observing Tables 11 and 12 and Table D in the Appendix. In this analysis, we will ignore the Unclassified subjects as we do not have any predictions for their behavior. Instead, we concentrate our attention on three types - the Competitive/Pecuniary $(\mathrm{S} \$ / \star)$ subjects in the Selfish treatment and Competitive $(\mathrm{A} \star)$ and Pecuniary $(\mathrm{A} \$)$ subjects in the Altruistic treatment.

Finding 10 The competitive frame induces greater giving by the Competitive subjects in the Rounds 2-10 of the Altruistic treatment.

As Table 11 and Table D in the Appendix show, while initially the Altruistic-Competitive 


\begin{tabular}{|c||c|c|c||c||c|c|c|}
\hline & $\mathrm{S} \$ / \star^{1}$ & $\mathrm{~S} ?^{1}$ & $\mathrm{~A} \$^{1}$ & & $\mathrm{~S} \$ / \star^{2-10}$ & $\mathrm{~S} ?^{2-10}$ & $\mathrm{~A} \$^{2-10}$ \\
\hline $\mathrm{S} ?^{1}$ & 21 & - & - & $\mathrm{S} ?^{2-10}$ & 0.5150 & - & - \\
$\mathrm{p}$-value & $>0.10$ & & & $\mathrm{p}$-value & 0.001 & & \\
\hline $\mathrm{A} \$^{1}$ & 11 & 14 & - & $\mathrm{A} \$^{2-10}$ & 0.1517 & 0.6667 & - \\
$\mathrm{p}$-value & $>0.10$ & $>0.10$ & & $\mathrm{p}$-value & $>0.10$ & 0.001 & \\
\hline $\mathrm{A} \star^{1}$ & 35 & 35 & 21 & $\mathrm{~A} \star^{2-10}$ & 0.8713 & 0.8571 & 0.7937 \\
$\mathrm{p}$-value & 0.1 & 0.1 & $>0.10$ & $\mathrm{p}$-value & 0.001 & 0.001 & 0.001 \\
\hline
\end{tabular}

Table 11: Pairwise comparisons of giving across different Non-Resolute types in Round 1 and Rounds 2-10 using Kolmogorov-Smirnov one-tail test statistics, with their respective statistical significance $p$.

subjects give an insignificantly higher amount than the Altruistic-Pecuniary subjects, they give significantly more than the Altruistic-Pecuniary subjects in the subsequent second through tenth rounds, and they are significantly more generous than the subjects in the Selfish treatment both initially and subsequently.

Furthermore, there is heterogeneity of the choice dynamics for different directional adjustment types.

\begin{tabular}{|c|c|c|}
\hline & test statistics & p-value \\
\hline $\mathrm{S} \$ / \star^{1}$ vs. $\mathrm{S} \$ / \star^{2-10}$ & 0.5803 & $p=0.01$ \\
\hline $\mathrm{S} ?^{1}$ vs. $\mathrm{S} ?^{2-10}$ & 0.4444 & $p=0.10$ \\
\hline $\mathrm{A} \$^{1}$ vs. $\mathrm{A} \$^{2-10}$ & 0.5556 & $p=0.05$ \\
\hline $\mathrm{A} \star^{1}$ vs. $\mathrm{A} \star^{2-10}$ & 0.6032 & $p=0.02$ \\
\hline
\end{tabular}

Table 12: Pairwise comparisons of giving by different Non-Resolute types in Round 1 and Rounds 2-10 using Kolmogorov-Smirnov one-tail test statistics, with their respective statistical significance $p$.

Finding 11 The giving of the Altruistic-Competitive subjects increases over time, while the giving of the other types decreases over time.

That is, the Altruistic-Competitive subjects give significantly more in the Rounds 2-10 than in the Round 1, while the reverse happens to the other types. In other words, the dynamics of Altruistic-Competitive subjects' behavior differs from that of all other types, including the other, Altruistic-Pecuniary type.

However, the previous Finding is hardly a surprise once we show further that the AltruisticPecuniary subjects actually behave as if they were in the Selfish treatment. It is clear from 
both Tables 11 and 12 that the giving of the Altruistic-Pecuniary subjects is not statistically different from the giving of the Selfish-Pecuniary/Competitive subjects - both in the first round and the subsequent second through tenth rounds.

Finding 12 The Pecuniary subjects in the Altruistic treatment behave in a similar fashion as the Pecuniary/Competitive subjects in the Selfish treatment.

This is a striking finding. First of all, it shows that the behavior of the subjects who are driven by pecuniary motives is frame independent. Second, it explains why the aggregate behavior of subjects in the "Altruistic" treatment became more self-regarding over time. This is simply because, statistically, several subjects in the "Altruistic" treatment behave similarly to those in the "Selfish" treatment.

In summary, we find considerable heterogeneity among subjects. Within the Altruistic treatment we have some subjects behaving competitively, while others use information on relative rank to infer the state of the (social) environment. We also found that the behavior of those seeking information is frame-independent; they are found in both the Altruistic and the Selfish treatments. Finally, we observe a minority of subjects who are not susceptible to any relative comparisons, and thus their behavior is in line with the "other-ignoring" neoclassical doctrine.

\section{Competition or Information?}

In this section we seek to understand several seemingly anomalous findings. In particular, Finding 12, that the behavior of some Non-Resolute subjects is insensitive to the competitive frame, Finding 11 that giving by these subjects declines with time, and as Finding 7 , that this decline cannot be explained by second-thought processes alone, as behavior in the Control treatment is quite different from the other two treatments. Specifically, we ask: why does the competitive design of the Altruistic treatment fail to stimulate giving among a subset of subjects? Could it be that the information on relative giving provided in both the Selfish and Altruistic treatments is processed by these subjects differently from what our model in Section 2 suggests?

When we created our experimental design, we did not expect to see frame-independent behavior beyond the noisy second-thought process observed in the Control treatment. Thus, given our experimental design, our answers to the question posed above is only speculative. However, we now think that some of the subjects, rather than being motivated by competition, are instead lead by information-based motives. While the subjects are never given any explicit information about the actual amounts kept/given away, they can still impute some of this information from the ordinal ranks, perhaps in tandem with some experimentation 
on their part. Thus, it is possible that the rankings convey pretty good information on the dollar allocation decisions of others, despite our efforts to avoid disclosing such information.

An obvious observation is that information about other subjects' choices may help boundedly rational subjects to learn how to "play the game." That is, if subjects are self-interested but confused about what is the best action to take even in a standard dictator game, they may eventually learn that the action that would maximize self-interest would involve giving nothing. Yet, let us use Table A in the Appendix to compare the number of subjects who gave nothing in the first period to the number of such subjects in the last (10th) period by treatment. In the Selfish treatment, this number increased from 4 in the first round to 11 in the last round, for the Altruistic treatment, this increase was from 6 to 12, while in the Control treatment there was a mere increase from 10 to 11. While all three treatments provided an ample opportunity for "second thought" introspective learning, only the Control treatment offered no opportunity for social learning, thus suggesting that if the learning hypothesis is correct it must be social learning that is the most important here.

However, we hypothesize that a different and more complex mechanism may also be at work. Suppose that some subjects care about behaving in a socially acceptable way. Subjects may or may not have their own beliefs about what is socially acceptable and what is not, and they may look for keys or signals based on others' behavior. The relative rankings, in tandem with some experimentation, may provide some indication of what might be socially acceptable - at least within each group of subjects. We further hypothesize that such kind of behavior might be driven by motives in the spirit of Samuelson [2004], rather than the competitive behavior in the spirit of Veblen [1899] and Frank [1985a]. In his pioneering work on information-based relative concerns, Samuelson [2004] suggested that relative comparisons may serve as a source of information about the state of the environment, and thus allow for social learning. That is, an individual might make "better" decisions if s/he took into account not only her/his own signal about the state of the environment, but also what the other surviving individuals did in the previous periods. In other words, one can update one's own estimate of the state of the environment by looking at what other people do.

To illustrate that this theory may be quite relevant to charitable giving, we remind the reader of a situation, familiar to many of us, wherein a departmental secretary passes around a request to donate money - either for a specific charity, or for a retirement/going-away present, etc. Anecdotal evidence suggests that quite a few individuals tend to ask about the amount of other people's donations before they make their own. Some do this for competitive reasons (these individuals tend to "top up" the typical amount), others may be uncertain about either the worthiness of the recipient or simply about the minimum donation one can get away with and survive in the current social environment (these individuals tend to make donations very close to the typical amount). While our model in Section 2 is suitable for modelling the first type of behavior, we think that Samuelson's [2004] approach might be more fruitful in explaining the second type of behavior as well as the behavior of some of the subjects in our experiment. 
Thus, consider a subject who would like to keep as much money as possible subject to behaving in a socially acceptable way. However she may be uncertain about how much keeping she can "get away" with and "survive", in the current social environment. She may reckon what is socially acceptable in a laboratory and what is not by observing how experimenter reacts to other people's choices. (Or whether there is any reaction at all.) The rankings of the amount kept in the Selfish treatment and of the amount given away in the Altruistic treatment convey some information as to what other people do (or at least whether subjects "got away" with lower amounts). Observing that some people "survived" in a given social environment by giving less (than the observer) say, because of the lack of any reaction from the experimenter, the individual may update her belief as to the level of acceptable giving. Once these subjects reckon that someone else "got away" with keeping everything, they may choose to follow suit (Sessions S1, S2, and A2 are particularly striking in this respect).

Let us sketch an alternative model of information-based behavior. ${ }^{19}$ Suppose there is an alternative, information-based type of subject, who rather than having concerns with relative position instead maximizes her utility from the private surplus $y_{i}=z_{i}-x_{i}$ subject to behaving in a socially acceptable way. That is, individual $i$ 's problem is:

$$
\max _{y_{i}} U_{i}^{I}\left(y_{i}\right) \text { subject to } y_{i} \leq \phi_{i}\left(y_{-i}, \alpha_{i}\right)
$$

so that the (interior) solution to the problem is

$$
y_{i}=\phi_{i}\left(y_{-i}, \alpha_{i}\right)
$$

Here $\phi_{i}\left(y_{-i}, \alpha_{i}\right)$ is a function that specifies for a given individual $i$ what is socially acceptable in the given circumstances, and $\phi_{i}(\cdot, \cdot)$ is non-decreasing in $y_{-i}$ and $\alpha_{i}{ }^{20}$

This general formulation of a "social acceptability" function $\phi_{i}(\cdot, \cdot)$ allows for several possibilities. First, if $\phi_{i}(\cdot, \cdot)$ is independent of $y_{-i}$, then the individual's beliefs of what is socially acceptable are independent of what other people do and instead are exogenously determined by the individual's own upbringing, culture, etc. (similar to Andreoni and Samuelson $[2004]) .^{21}$

Second, which is important for our design, the individual's beliefs of what is socially acceptable may also depend on what other people do in a given circumstance. Given the lack of relevant research, we are agnostic about how people form beliefs about what is socially acceptable. However, we can speculate that other people's behavior may enter one's beliefs in a complicated way (which may be specific to an individual). That is, one may care about statistics of other people's behavior, similar to a "beauty contest". Examples of such

\footnotetext{
${ }^{19}$ Please note that this alternative information-based model is a by-product of our experiment. We developed it to explain the behavior of subjects who did not conform to our initial hypotheses.

${ }^{20}$ In our experiment, the social acceptability function is bounded by design, i.e. $0 \leq \phi_{i}(\cdot, \cdot) \leq z_{i}$.

${ }^{21}$ We hypothesize that the behavior of our Resolute subjects may be governed by such exogenously determined beliefs.
} 
concerns might include the average choice (e.g. $\left.\phi_{i}\left(y_{-i}, \alpha_{i}\right)=\alpha_{i} \bar{y}_{-i}\right)$, the median choice (e.g. $\phi_{i}\left(y_{-i}, \alpha_{i}\right)=\alpha_{i}$ med $\left.y_{-i}\right)$, or the minimum choice (e.g. $\left.\phi_{i}\left(y_{-i}, \alpha_{i}\right)=\alpha_{i} \min y_{-i}\right)$. One can also imagine that there are more complicated forms, whereby an individual cares about the entire distribution of people's choices.

As $\phi_{i}(\cdot, \cdot)$ is non-decreasing in $y_{-i}$, a subject who is concerned about relative giving for informational reasons would decrease her giving whenever the relative giving by other subjects (which, with some experimentation, can be imputed from the rank table) is less than expected. Moreover, this type of behavior would be independent of the competitive frame. As each round of giving provides subjects with more opportunities to update information about what is socially acceptable, information-driven individuals would decrease their giving with time. ${ }^{22}$

Notice that the directional adjustment behavior of a subject whose behavior is informationbased is similar to the behavior of the Pecuniary types in both the Selfish and Altruistic treatments. Thus, the Altruistic treatment provides us with a natural possibility of separating the competition-based ("Veblenian") and information-based ("Samuelsonian") relative concerns. However, our experimental design does not allow us to distinguish between the two types of relative concerns in the Selfish treatment.

Even more likely, the two types of motivations, competitive and informational, may coexist. The directional adjustment types that we introduced earlier may in fact be classified according to which motivation turns out to be dominant - information or competition. As the above Finding 11 indicates, for the Altruistic-Competitive subjects, the information effects may be less strong than the competitive pressures, while for the Altruistic-Pecuniary subjects it is the other way around. For the Selfish-Competitive/Pecuniary subjects the two motives work in the same direction, possibly enhancing each other. Consequently, relative to the Control treatment, other-regarding behavior is frustrated in the Selfish treatment, while it is encouraged in the Altruistic treatment. ${ }^{23}$

\section{Conclusions}

We have explored the effects of non-monetary, intrinsic competitive motives on altruistic behavior by modifying the standard dictator experiment and creating two competitive treatments along with one control treatment. Our hypothesis that competition stimulates giving, in general, is correct, yet the mechanism by which competitive altruism works is different

\footnotetext{
${ }^{22}$ Such social learning might be particularly fast if $\phi_{i}\left(y_{-i}, \alpha_{i}\right)=\alpha_{i} \min y_{-i}$, with $\alpha_{i}<1$.

${ }^{23}$ Furthermore, it is plausible that the exogenously formed altruistic motive, discussed earlier, may also interact with information gathering. If this is the case, the Unclassified subjects in the Selfish treatment may in fact possess relatively strong, exogenously-formed altruistic motives which nevertheless get "frustrated" by the imputed information about what is socially acceptable.
} 
from what one might expect. First, as our findings for the Control treatment indicate, in the absence of social content, there are more subjects who never change their allocation decisions and tend to behave in a more self-regarding matter. That is, the Resolute subjects in the Control treatment give less on average. Next, the comparison of the first-round choices of those subjects who changed their choices at least once across the three treatments (the Non-Resolute subjects) shows that in the absence of the competitive Altruistic frame, the initial behavior of the Non-Resolute subjects is more self-regarding. Lastly, the competitive Altruistic frame works to slow down (but not prevent or reverse) the rate of decline in giving. This decline suggests that using competitive urges as mechanism to stimulate altruistic behavior may ultimately be fruitless. On the other hand, if there were a constant flow of new entrants (dictators), as would seem natural e.g. in charitable giving, this decline might be (permanently) arrested.

Finally, as our further subject-level analysis shows, human altruistic behavior is much more complicated, and there is a lot of heterogeneity in individual behavior. For a majority of subjects, both competitive frames provide some informational content, the effect of which may be frame-independent. This informational content counteracts the competitive pressures in the Altruistic treatment and enhances the competitive pressures in the Selfish treatment. However this informational effect is not universal for all subjects. In the Altruistic treatment, the Altruistic-Competitive subjects gave away on average $\$ 5.60$ (or $56 \%$ of the funds). In other words, for some subjects the competitive altruism does stimulate giving!

However, the informational effect of competitive environment should not be taken too lightly, as it may contribute to the Pecuniary subjects decreasing their giving to an average of $\$ 1.21$ (or $12.1 \%$ of the funds) in the Altruistic treatment, and to $\$ 0.86$ (or $8.6 \%$ ) in the Selfish treatment, followed by the Unclassified subjects in the Selfish treatment (\$1.63 or $16.3 \%$ of the funds). Thus, the success of a design mechanism employing competitive altruism (such as ranking by Slate magazine) depends crucially on the composition of the participants.

This analysis complements much recent work which seeks to understand how extrinsic considerations may interact with intrinsic motivations. As predicted, in the aggregate, subjects' other-regarding behavior was frustrated when competitive pressures acted against it, and was encouraged when competitive pressures where aligned with motives for otherregarding behavior. Yet, as some subjects demonstrated insensitivity to the social competitive frame, the difference between the two competitive treatments comes primarily from those subjects who were responsive to the competitive environment - either for competitive or informational reasons.

One possibility we have not explored here is that philanthropic behavior may involve signaling of wealth (akin to money burning), and thus it would be of interest to pursue a study that explores how the heterogeneity of endowments as well as the nature of endowments affects giving. We nevertheless would like to emphasize that we found substantial heterogeneity in subjects' giving behavior even when subjects had identical endowments. Thus, 
we see our study as a logical initial step towards understanding competitive philanthropy.

\section{References}

Andreoni, James (1990), "Impure altruism and donations to public goods: a theory of warm-glow giving", Economic Journal 100: 464-477.

Andreoni, James (1995), "Cooperation in Public-Goods Experiments: Kindness or Confusion?", American Economic Review 85 (4): 891-904.

Andreoni, James, and Larry Samuelson (2003), "Building rational cooperation", working paper.

Ball, Sheryl, Catherine Eckel, Philip Grossman and William R. Zame (2001), "Status in Markets," Quarterly Journal of Economics 116: 161-188.

Barclay, Pat (2004), "Trustworthiness and competitive altruism can also solve the "tragedy of the commons"", Evolution and Human Behavior, forthcoming.

Becker, Gary (1974), "A Theory of Social Interaction", Journal of Political Economy 82: 1063-93.

Bénabou, Roland and Jean Tirole (2003), "Intrinsic and Extrinsic Motivation", Review of Economic Studies 70: 489-520.

Bolton, Gary E. (1991), "A Comparative Model of Bargaining", American Economic Review, December 1991, 81(5): 1096-1136.

Bolton, Gary E. and Axel Ockenfels (2000), "ERC: A Theory of Equity, Reciprocity and Competition", American Economic Review, 92(1): 166-193.

Camerer, C.F. (2003), Behavioral Game Theory Princeton: Princeton University Press.

Cason, Timothy N. and Vai-Lam Mui (1998), "Social Influence in the Sequential Dictator Game", Journal of Mathematical Psychology 42: 248-265.

Dowd, Maureen 1996), "Ted's Excellent Idea", New York Times, August 22, 1996, p. A25.

Engers, Maxim, and Brian McManus (2004), "Charity Auctions", working paper.

Forsythe, Robert, Joel Horowitz, N.E. Savin, and Martin Sefton (1994), "Fairness in Simple Bargaining Experiments", Games and Economic Behavior 6: 347-369. 
Frank, Robert H. (1985a), Choosing the Right Pond: Human Behavior and the Quest for Status, New York: Oxford University Press.

Frank, Robert H. (1985b), "The demand for unobservable and other positional goods", American Economic Review 75(1): 101-116.

Glazer, A. and K.A. Konrad (1996), "A Signalling Explanation for Charity," American Economic Review, 86 (4): 1019-1028.

Gneezy, Uri (2003), "The W effect of incentives", working paper.

Gneezy, Uri and Aldo Rustichini (2000), "Pay Enough or Don't Pay at All", Quarterly Journal of Economics 115 (3): 791-810.

Harbaugh, William (1998), "The prestige motive for making charitable transfers", American Economic Review Papers and Proceedings, May 1998: 277-282.

Hoffman, E., K. McCabe, K. Shachat, and V. L. Smith (1994), "Preferences, Property Rights and Anonymity in Bargaining Games", Games and Economic Behavior 7: 346380.

Hopkins, Ed and Tatiana Kornienko (2004) "Running to Keep in the Same Place: Consumer Choice as a Game of Status", American Economic Review, September 2004, 94 (4): 1085-1107.

Kahneman, D. and A. Tversky (1979), Prospect Theory: An Analysis of Decision Under Risk," Econometrica 47, 263-91.

Kumru, Cagri and Lise Vesterlund (2004), "The Effect of Status on Charitable Giving", working paper.

Noussair, C.N., C.R. Plott and R.G. Riezman (1995), "An Experimental Investigation of the Patterns of International Trade," American Economic Review 85 (3), 462-491.

Postlewaite, Andrew (1998), "The social basis of interdependent preferences", European Economic Review 42: 779-800.

Salmon, Timothy C. and R. Mark Isaac (2004), "Revenue from the Saints, the Showoffs, and the Predators: Comparisons of Auctions with Price-Preference Values", working paper.

Samuelson, Larry (2004), "Information-based relative consumption effects", Econometrica, 72 (1): 93-118.

Veblen, Thorstein (1899), The Theory of the Leisure Class, New York: Macmillan.

Weber, Roberto A. (2003), "Learning and transfer of learning with no feedback: An experimental test across games", working paper. 
Weiss, Yoram and Chaim Fershtman (1998), "Social status and economic performance: a survey", European Economic Review 42: 801-820. 
Appendix 
Table A: Experimental Data, all sessions all rounds (rounds are columns labeled 1-10). S1 stands for the first session in the Selfish treatment, A1, C1 are first sessions of the Altruistic and Control treatments, etc.). End-of-period rankings (1-5, leftmost column) of subject letter IDs are shown as presented to subjects. Ties are indicated by multiple letters at the same rank. The actual amounts given by subjects [in square brackets] were not publicly disclosed. The last column reports each subject's gender (Letter ID: Gender).

\begin{tabular}{|c|c|c|c|c|c|c|c|c|c|c|c|}
\hline S1 & 1 & 2 & 3 & 4 & 5 & 6 & 7 & 8 & 9 & 10 & Gender \\
\hline $\begin{array}{l}1 \\
2 \\
3 \\
4 \\
5\end{array}$ & $\begin{array}{c}\mathrm{A}[3] \\
\mathrm{BE}[5]\end{array}$ & $\overline{\mathrm{ABCE}[0]}$ & $\begin{array}{l}\mathrm{A}[1] \\
\mathrm{B}[2] \\
\mathrm{D}[3]\end{array}$ & $\mathrm{BCE}[0]$ & $\overline{\mathrm{ACDE}}[0]$ & $\overline{A C D E}[0]$ & $\mathrm{ABCDE}[0]$ & $\mathrm{ABCDE}[0]$ & $\mathrm{ABCDE}[0]$ & $\mathrm{ABCDE}[0]$ & $\begin{array}{c}\text { A: M } \\
\text { B: F } \\
\text { C: M } \\
\text { D: M } \\
\text { E: M }\end{array}$ \\
\hline S2 & 1 & 2 & $\begin{array}{l}3 \\
3 \\
\end{array}$ & 4 & 5 & 6 & 7 & 8 & 9 & 10 & Gender \\
\hline $\begin{array}{l}1 \\
2 \\
3 \\
4 \\
5\end{array}$ & $\begin{array}{c}\mathrm{K}[0.01] \\
\mathrm{O}[2] \\
\mathrm{N}[3]\end{array}$ & $\begin{array}{c}\mathrm{O}[1] \\
\mathrm{N}[3.5]\end{array}$ & KLMO [0] & $\begin{array}{c}\mathrm{N}[0.5] \\
\mathrm{O}[1]\end{array}$ & KLMN[0] & $\overline{\text { KLMO }[0]}$ & $\begin{array}{c}\mathrm{N}[0.5] \\
\mathrm{O}[1]\end{array}$ & KLMO [0] & KLMN $[0]$ & $\overline{\text { KLMO }[0]}$ & $\begin{array}{l}\mathrm{K}: \mathrm{M} \\
\mathrm{L}: \mathrm{M} \\
\mathrm{M}: \mathrm{F} \\
\mathrm{N}: \mathrm{M} \\
\mathrm{O}: \mathrm{F}\end{array}$ \\
\hline S3 & 1 & 2 & 3 & 4 & 5 & 6 & 7 & 8 & 9 & 10 & Gender \\
\hline 1 & $\mathrm{~B}[0.02]$ & $\mathrm{C}[0]$ & $\mathrm{B}[0.01]$ & $\mathrm{B}[0.02]$ & $\mathrm{CE}[0]$ & $\mathrm{AE}[0]$ & $\overline{A C}[0]$ & $\mathrm{C}[0]$ & $\mathrm{AE}[0]$ & $\mathrm{AE}[0]$ & $A: M$ \\
\hline 2 & $\mathrm{~A}[3]$ & $\mathrm{B}[0.01]$ & $\mathrm{A}[2]$ & $\mathrm{C}[1]$ & & & & $\mathrm{B}[0.01]$ & & & B: $M$ \\
\hline $\begin{array}{l}3 \\
4\end{array}$ & $\mathrm{CDE}[5]$ & $\begin{array}{c}\mathrm{A}[3] \\
\mathrm{DE}[5]\end{array}$ & $\mathrm{CE}[2.5]$ & $\mathrm{AE}[2]$ & $\begin{array}{c}\mathrm{B}[0.03] \\
\mathrm{A}[1]\end{array}$ & $\begin{array}{c}\mathrm{B}[0.01] \\
\mathrm{C}[0.5]\end{array}$ & $\begin{array}{c}\mathrm{B}[0.01] \\
\mathrm{DE}[5]\end{array}$ & $\mathrm{AE}[1]$ & $\begin{array}{c}\mathrm{B}[0.01] \\
\mathrm{C}[0.5]\end{array}$ & $\begin{array}{l}\mathrm{B}[0.01] \\
\mathrm{C}[0.25]\end{array}$ & $\begin{array}{l}\text { C: F } \\
D: F\end{array}$ \\
\hline 5 & & & $\mathrm{D}[5]$ & $\mathrm{D}[5]$ & $\mathrm{D}[5]$ & $\mathrm{D}[5]$ & & $\mathrm{D}[5]$ & $\mathrm{D}[5]$ & & $\mathrm{E}: \mathrm{M}$ \\
\hline S4 & 1 & 2 & 3 & 4 & 5 & 6 & 7 & 8 & 9 & 10 & Gender \\
\hline 1 & $\mathrm{~F}[0.01]$ & $\mathrm{F}[0.01]$ & $\mathrm{F}[0.01]$ & $\mathrm{F}[0.01]$ & $\mathrm{F}[0.01]$ & FI[0.01] & $\mathrm{G}[0]$ & $\mathrm{F}[0]$ & $\mathrm{F}[0]$ & FG[0] & $F: F$ \\
\hline 2 & $\mathrm{I}[2]$ & $\mathrm{G}[1]$ & $\mathrm{I}[1]$ & $\mathrm{G}[1]$ & $\mathrm{G}[0.1]$ & & $\mathrm{F}[0.01]$ & $\mathrm{I}[0.75]$ & $\mathrm{I}[0.2]$ & & G: F \\
\hline 3 & $\mathrm{G}[3.5]$ & $\mathrm{I}[2]$ & $\mathrm{HJ}[3]$ & $\mathrm{I}[1.5]$ & $\mathrm{H}[2]$ & $\mathrm{HJ}[3]$ & $\mathrm{I}[0.5]$ & $\mathrm{GH}[2]$ & $\mathrm{H}[1]$ & $\mathrm{I}[0.05]$ & $\mathrm{H}: \mathrm{M}$ \\
\hline 4 & $\mathrm{HJ}[5]$ & $\mathrm{H}[3]$ & & $\mathrm{HJ}[4]$ & $\mathrm{I}[2.25]$ & & $\mathrm{HJ}[3]$ & & $\mathrm{G}[2.1]$ & $\mathrm{J}[2]$ & I: M \\
\hline 5 & & $\mathrm{~J}[4]$ & $\mathrm{G}[5]$ & & $\mathrm{J}[3]$ & $\mathrm{G}[6]$ & & $\mathrm{J}[3]$ & $\mathrm{J}[3]$ & $\mathrm{H}[5]$ & $\mathrm{J}: \mathrm{F}$ \\
\hline$\overline{\mathrm{A} 1}$ & 1 & 2 & 3 & 4 & 5 & 6 & 7 & 88 & 99 & 10 & Gender \\
\hline 1 & KLN[5] & $\mathrm{K}[6]$ & $\mathrm{L}[6]$ & $\mathrm{K}[6]$ & $\mathrm{KL}[6]$ & $\mathrm{N}[10]$ & $\mathrm{K}[8]$ & $\mathrm{K}[8]$ & $\mathrm{L}[8]$ & $\mathrm{L}[8.01]$ & $\mathrm{K}: \mathrm{F}$ \\
\hline 2 & & $\operatorname{LN}[5]$ & $\mathrm{K}[5]$ & $\mathrm{L}[6.5]$ & & $\mathrm{KL}[6]$ & $\mathrm{L}[7]$ & $\mathrm{L}[7.5]$ & $\mathrm{K}[5]$ & $\mathrm{K}[6]$ & $\mathrm{L}: \mathrm{F}$ \\
\hline 3 & & & $\mathrm{MNO}[0]$ & $\mathrm{N}[0.01]$ & $\mathrm{MNO}[0]$ & & $\mathrm{N}[3]$ & $\operatorname{MNO}[0]$ & $\operatorname{MNO}[0]$ & $\mathrm{MNO}[0]$ & M: M \\
\hline $\begin{array}{l}4 \\
5\end{array}$ & $\operatorname{MO}[0]$ & $\mathrm{MO}[0]$ & & $\mathrm{MO}[0]$ & & $\mathrm{MO}[0]$ & $\mathrm{MO}[0]$ & & & & $\begin{array}{l}N: F \\
O: F\end{array}$ \\
\hline A2 & 1 & 2 & 3 & 4 & 5 & 6 & 7 & 8 & 9 & 10 & Gender \\
\hline 1 & GI[5] & $F[6]$ & $1[6]$ & $1[6]$ & $1[6]$ & $1[6]$ & $1[6]$ & $1[6]$ & $1[6]$ & $1[6]$ & $F: F$ \\
\hline $\begin{array}{l}2 \\
3 \\
4\end{array}$ & F HJ $[0]$ & $\begin{array}{c}\mathrm{I}[5] \\
\mathrm{GHJ}[0]\end{array}$ & $\mathrm{FGHJ}[0]$ & FGHJ $[0]$ & $\mathrm{FGHJ}[0]$ & $\mathrm{FGHJ}[0]$ & $\mathrm{FGHJ}[0]$ & $\mathrm{FGHJ}[0]$ & $\mathrm{FGHJ}[0]$ & $\mathrm{FGHJ}[0]$ & $\begin{array}{l}\text { G: } \\
\text { H: M } \\
\text { I: M }\end{array}$ \\
\hline 5 & & & & & & & & & & & $\mathrm{~J}: \mathrm{M}$ \\
\hline A3 & 1 & 2 & 3 & 4 & 5 & 6 & 7 & 8 & 9 & 10 & Gender \\
\hline 1 & $\mathrm{G}[6]$ & $J[9]$ & $\mathrm{J}[9]$ & $\mathrm{H}[9]$ & $\mathrm{H}[8]$ & $\mathrm{G}[6.15]$ & $\mathrm{GH}[6]$ & $\mathrm{H}[7]$ & $\mathrm{G}$ G[6.25] & GI[5] & $F: M$ \\
\hline 2 & HIJ [5] & $\mathrm{H}[6]$ & $\mathrm{H}[7]$ & GIJ $[5]$ & $\mathrm{I}[5]$ & $\mathrm{I}[5]$ & & $\mathrm{G}[6]$ & $\mathrm{I}[5]$ & & G: M \\
\hline 3 & & $\mathrm{G}[5.01]$ & $\mathrm{I}[5]$ & & $\mathrm{G}[4.5]$ & $\mathrm{H}[1]$ & $\mathrm{I}[5]$ & $\mathrm{I}[5]$ & $\mathrm{H}[1]$ & F HJ $[0]$ & $\mathrm{H}: \mathrm{M}$ \\
\hline 4 & & $\mathrm{FI}[5]$ & $\mathrm{G}[3]$ & & $\mathrm{FJ}[0]$ & $\mathrm{FJ}[0]$ & $\mathrm{F} J[0]$ & $\mathrm{F} J[0]$ & $\mathrm{FJ}[0]$ & & I: F \\
\hline 5 & $\mathrm{~F}[0]$ & & $\mathrm{F}[0]$ & $\mathrm{F}[0]$ & & & & & & & $\mathrm{J}: \mathrm{F}$ \\
\hline $\mathrm{A} 4$ & 1 & 2 & 3 & 4 & 5 & 6 & 7 & 8 & 9 & 10 & Gender \\
\hline 1 & KMN[5] & $O[6]$ & $0[5.5]$ & $\mathrm{M}[7]$ & $\mathrm{M}[6]$ & $0[6.25]$ & MO [6] & $O[6]$ & $\mathrm{M}[6]$ & $\mathrm{M}[6]$ & $\mathrm{K}: \mathrm{F}$ \\
\hline 2 & & $\mathrm{KM}[5]$ & $\mathrm{K}[5]$ & $\mathrm{O}[5.25]$ & $\mathrm{O}[5.75]$ & $\mathrm{KM}[5]$ & & $\mathrm{K}[5]$ & $O[5.5]$ & $\mathrm{KO}[5]$ & L: M \\
\hline 3 & & & $\mathrm{M}[4]$ & $\mathrm{K}[5]$ & $\mathrm{K}[5]$ & & $\mathrm{K}[5]$ & $\mathrm{N}[3]$ & $\mathrm{K}[5]$ & & $M: M$ \\
\hline 4 & $\mathrm{O}[4.5]$ & $\mathrm{N}[4]$ & LN $[0]$ & $\mathrm{N}[1]$ & $\mathrm{LN}[0]$ & $\mathrm{N}[2]$ & $\operatorname{LN}[0]$ & $\operatorname{LM}[0]$ & $\mathrm{LN}[0]$ & $\operatorname{LN}[0]$ & $\mathrm{N}: \mathrm{M}$ \\
\hline 5 & $\mathrm{~L}[3]$ & $\mathrm{L}[0]$ & & $\mathrm{L}[0]$ & & $\mathrm{L}[0]$ & & & & & $\mathrm{O}: \mathrm{M}$ \\
\hline$\overline{\mathrm{C} 1}$ & 1 & 22 & 3 & 4 & 25 & 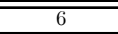 & 7 & 8 & 99 & 10 & 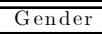 \\
\hline 1 & G[0] & $\mathrm{H}[4.5]$ & $\mathrm{H}[0.5]$ & $\mathrm{H}[0.5]$ & $\mathrm{H}[5]$ & $T[0]$ & $J[2]$ & $T[0]$ & G[0] & $\mathrm{H}[5]$ & $F: F$ \\
\hline 2 & $\mathrm{H}[0]$ & $\mathrm{J}[5]$ & $\mathrm{J}[4]$ & $\mathrm{G}[0]^{\mathrm{T}}$ & $\mathrm{J}[2]$ & $\mathrm{H}[5]$ & $\mathrm{G}[0]$ & $J[3]$ & $\mathrm{I}[0]$ & $\mathrm{F}[0]$ & G: M \\
\hline 3 & $F[0]$ & $\mathrm{G}[0]$ & $\mathrm{F}[0] \mathrm{I}[0]$ & $\mathrm{I}[0]$ & $\mathrm{G}[0]$ & $\mathrm{G}[0]$ & $\mathrm{H}[2]$ & $\mathrm{H}[0]$ & $\mathrm{J}[4]$ & $\mathrm{I}[0]$ & $\mathrm{H}: \mathrm{F}$ \\
\hline 4 & $J[5]$ & $\mathrm{I}[0]$ & & $J[3]$ & $\mathrm{F}[0]$ & $\mathrm{J}[1]$ & $\mathrm{F}[0]$ & $\mathrm{G}[0]$ & $\mathrm{F}[0]$ & $\mathrm{J}[5]$ & I: F \\
\hline 5 & $\begin{array}{l}\mathrm{I}[0] \\
0\end{array}$ & $\mathrm{~F}[0]$ & $\mathrm{G}[0]$ & $\mathrm{F}[0]$ & $\begin{array}{l}1[0] \\
\end{array}$ & $\begin{array}{l}\mathrm{F}[0] \\
\end{array}$ & $\mathrm{I}[0]$ & $\mathrm{F}[0]$ & $\mathrm{H}[3]$ & $\mathrm{G}[0]$ & $\mathrm{J}: \mathrm{F}$ \\
\hline $\mathrm{C} 2$ & 1 & 2 & 3 & 4 & 5 & 6 & 7 & 8 & 9 & 10 & Gender \\
\hline 1 & $\mathrm{~A}[4]$ & $\mathrm{B}[0]$ & $\mathrm{D}[0]$ & $\mathrm{A}[0]$ & $\mathrm{A}[5]$ & $\mathrm{A}[2]$ & $\mathrm{B}[0]$ & $\mathrm{D}[0]$ & $\mathrm{B}[0]$ & $\mathrm{D}[0]$ & $A: M$ \\
\hline 2 & $\mathrm{D}[0]$ & $\mathrm{E}[1]$ & $\mathrm{B}[0]$ & $\mathrm{E}[0.5]$ & B [0] & $\mathrm{B}[0]$ & $\mathrm{C}$ & $\mathrm{E}[0]$ & $\mathrm{C}[0]$ & $\mathrm{A}[$ & B: F \\
\hline 3 & $\mathrm{C}[0]$ & $\mathrm{D}[0]$ & $\mathrm{A}[7] \mathrm{E}[0]$ & $\mathrm{D}[0]$ & $\mathrm{C}[0]$ & $\mathrm{E}[1]$ & $\mathrm{E}[0]$ & $\mathrm{A}[0]$ & $\mathrm{E}[0]$ & $\mathrm{C}[0]$ & C: F \\
\hline 4 & $\mathrm{~B}[0]$ & $\mathrm{C}[0]$ & & $\mathrm{B}[0]$ & $\mathrm{D}[0]$ & $\mathrm{C}[0]$ & $\mathrm{D}[0]$ & $\mathrm{C}[0]$ & $\mathrm{A}[6]$ & $\mathrm{E}[0]$ & D: F \\
\hline 5 & $\mathrm{E}[0]$ & $\mathrm{A}[2]$ & $\mathrm{C}[0]$ & $\mathrm{C}[0]$ & $\mathrm{E}[0]$ & $\mathrm{D}[0]$ & $\mathrm{A}[6]$ & $\mathrm{B}[0]$ & $\mathrm{D}[0]$ & $\mathrm{B}[0]$ & E: F \\
\hline C3 & 1 & 2 & 3 & 4 & 5 & 6 & 7 & 8 & 9 & 10 & Gender \\
\hline 1 & $\mathrm{~K}[5]$ & $\begin{array}{l}\mathrm{L}[0.5] \\
\end{array}$ & M[5] & $\mathrm{K}[5]$ & $\mathrm{O}[5]$ & $\mathrm{M}[0]$ & $\begin{array}{lll}\mathrm{N}[1] \\
\end{array}$ & $\mathrm{N}[1]$ & $\begin{array}{l}\mathrm{M}[2] \\
\end{array}$ & $\begin{array}{l}M[2] \\
\end{array}$ & $\mathrm{K}: \mathrm{M}$ \\
\hline 2 & $\mathrm{~L}[1]$ & $\mathrm{O}[1]$ & $\mathrm{N}[1]$ & $\mathrm{O}[1]$ & $\mathrm{M}[5.5]$ & $\mathrm{O}[5]$ & $\mathrm{O}[5]$ & $\mathrm{O}[0]$ & $\mathrm{L}[3]$ & $\mathrm{L}[2]$ & $\mathrm{L}: \mathrm{F}$ \\
\hline 3 & $\mathrm{M}[2]$ & $\mathrm{N}[1]$ & $\mathrm{O}[1]$ & $\mathrm{N}[1]$ & $\mathrm{K}[5]$ & $\mathrm{L}[0]$ & $\mathrm{M}[3]$ & $\mathrm{L}[0]$ & $\mathrm{O}[0]$ & $\mathrm{O}[0]$ & $\mathrm{M}: \mathrm{M}$ \\
\hline 4 & O $[5]$ & $\mathrm{M}[2]$ & $\mathrm{L}[4]$ & $\mathrm{M}[0]$ & $\mathrm{L}[1]$ & $\begin{array}{l}2[0] \\
\mathrm{K}[5]\end{array}$ & K $[5]$ & $\begin{array}{l}\mathrm{M}[0] \\
\text { lo }\end{array}$ & K $[5]$ & $\mathrm{N}[1]$ & $\mathrm{N}: \mathrm{F}$ \\
\hline 5 & $\mathrm{~N}[1]$ & $\mathrm{K}[5]$ & $\mathrm{K}[5]$ & $\mathrm{L}[5]$ & $\mathrm{N}[1]$ & $\mathrm{N}[1]$ & $\mathrm{L}[0.5]$ & $\mathrm{K}[5]$ & $\mathrm{N}[1]$ & $\mathrm{K}[5]$ & $\mathrm{O}: \mathrm{F}$ \\
\hline $\mathrm{C} 4$ & 1 & 2 & 3 & 4 & 5 & 6 & 7 & 8 & 9 & 10 & Gender \\
\hline 1 & $\mathrm{D}[5]$ & $\mathrm{D}[3]$ & $\mathrm{E}[0]$ & $\mathrm{D}[5]$ & $\mathrm{A}[3]$ & $\mathrm{E}[0]$ & $\mathrm{B}[0]$ & $\mathrm{E}[0]$ & $\mathrm{B}[0]$ & $\mathrm{D}[5]$ & $\mathrm{A}: \mathrm{M}$ \\
\hline 2 & $\mathrm{C}[5]$ & $\mathrm{B}[0]$ & $\mathrm{A}[0]$ & $\mathrm{A}[1]$ & $\mathrm{E}[0]$ & $\mathrm{C}[5]$ & $\mathrm{D}[2]$ & $\mathrm{D}[6]$ & $\mathrm{A}[0]$ & $\mathrm{C}[5]$ & B : F \\
\hline 3 & $\mathrm{E}[0]$ & $\mathrm{A}[2]$ & $\mathrm{D}[4]$ & $\mathrm{B}[0]$ & $\mathrm{B}[0]$ & $\mathrm{A}[2]$ & $\mathrm{C}[5]$ & $\mathrm{A}[0]$ & $\mathrm{D}[3]$ & $\mathrm{A}[1]$ & C: M \\
\hline 4 & $\mathrm{~A}[2]$ & $\mathrm{E}[0]$ & $\mathrm{C}[5]$ & $\mathrm{E}[0]$ & $\mathrm{C}[4]$ & $\mathrm{D}[4.5]$ & $\mathrm{A}[1]$ & $\mathrm{C}[5]$ & $\mathrm{E}[0]$ & $\mathrm{E}[0]$ & D: M \\
\hline 5 & $\mathrm{~B}[0]$ & $\mathrm{C}[5]$ & $\mathrm{B}[0]$ & $\mathrm{C}[5]$ & $\mathrm{D}[6]$ & $\begin{array}{l}\mathrm{B}[0] \\
\end{array}$ & $\mathrm{E}[0]$ & $\mathrm{B}[0]$ & $\mathrm{C}[5]$ & $\mathrm{B}[0]$ & $E: F$ \\
\hline
\end{tabular}


Table B: Directional adjustment in all three treatments - by subject. ( represents an increase in giving, $\Downarrow$ represents a decrease in giving, $\equiv$ represents no change in giving; S1 stands for the first session in the Selfish treatment, etc.; Subject 1's letter ID is either A, F, or K; Subject 2's letter ID is either B, G, or L, and so on).

\begin{tabular}{|c|c|c|c|c|c|c|c|c|c|c|c|c|c|c|c|c|}
\hline & & & je & & & ojec & & & ojes & & $\mathrm{Su}$ & jjec & & $\mathrm{Su}$ & jec & \\
\hline Session & Rank & 介 & $\equiv$ & $\Downarrow$ & 介 & $\equiv$ & $\Downarrow$ & 介 & $\equiv$ & $\Downarrow$ & 介 & $\equiv$ & $\Downarrow$ & 介 & $\equiv$ & $\Downarrow$ \\
\hline S1 & $\begin{array}{c}\text { Top } \\
\text { Middle } \\
\text { Bottom }\end{array}$ & 1 & $\begin{array}{l}5 \\
1\end{array}$ & 2 & 2 & $\begin{array}{l}3 \\
1\end{array}$ & $\begin{array}{l}1 \\
2\end{array}$ & & 9 & & 1 & $\begin{array}{l}5 \\
1\end{array}$ & 2 & & 8 & 1 \\
\hline $\mathrm{S} 2$ & $\begin{array}{c}\text { Top } \\
\text { Middle } \\
\text { Bottom }\end{array}$ & & 8 & 1 & & 9 & & & 9 & & $\begin{array}{l}2 \\
1 \\
1\end{array}$ & & $\begin{array}{l}1 \\
4\end{array}$ & 3 & & $\begin{array}{l}2 \\
4\end{array}$ \\
\hline S3 & $\begin{array}{c}\text { Top } \\
\text { Middle } \\
\text { Bottom }\end{array}$ & 1 & $\begin{array}{l}2 \\
2\end{array}$ & 4 & 2 & 5 & $\begin{array}{l}1 \\
1\end{array}$ & 3 & 1 & $\begin{array}{l}4 \\
1\end{array}$ & & 9 & & 1 & $\begin{array}{l}2 \\
1\end{array}$ & $\begin{array}{l}3 \\
2\end{array}$ \\
\hline $\mathrm{S} 4$ & $\begin{array}{c}\text { Top } \\
\text { Middle } \\
\text { Bottom }\end{array}$ & & 8 & 1 & $\begin{array}{l}1 \\
3\end{array}$ & & $\begin{array}{l}3 \\
2\end{array}$ & 3 & 2 & $\begin{array}{l}1 \\
3\end{array}$ & $\begin{array}{l}1 \\
3\end{array}$ & 1 & 4 & 1 & 3 & 4 \\
\hline A1 & $\begin{array}{c}\text { Top } \\
\text { Middle } \\
\text { Bottom }\end{array}$ & $\begin{array}{l}1 \\
3\end{array}$ & 3 & 2 & $\begin{array}{l}1 \\
5\end{array}$ & 2 & 1 & & 9 & & 2 & $\begin{array}{l}1 \\
2\end{array}$ & $\begin{array}{l}1 \\
3\end{array}$ & & 9 & \\
\hline $\mathrm{A} 2$ & $\begin{array}{c}\text { Top } \\
\text { Middle } \\
\text { Bottom }\end{array}$ & 1 & 7 & 1 & & 8 & 1 & & 9 & & 1 & 8 & & & 9 & \\
\hline A3 & $\begin{array}{c}\text { Top } \\
\text { Middle } \\
\text { Bottom }\end{array}$ & 1 & 7 & 1 & 3 & 1 & $\begin{array}{l}3 \\
2\end{array}$ & $\begin{array}{l}1 \\
4\end{array}$ & & $\begin{array}{l}3 \\
1\end{array}$ & & $\begin{array}{l}8 \\
1\end{array}$ & & 1 & $\begin{array}{l}1 \\
5\end{array}$ & \\
\hline $\mathrm{A} 4$ & $\begin{array}{c}\text { Top } \\
\text { Middle } \\
\text { Bottom }\end{array}$ & & 1 & & & 8 & 1 & $\begin{array}{l}2 \\
1\end{array}$ & 2 & $\begin{array}{l}3 \\
1\end{array}$ & 3 & 1 & $\begin{array}{l}1 \\
4\end{array}$ & 3 & 1 & \\
\hline $\mathrm{C} 1$ & $\begin{array}{c}\text { Top } \\
\text { Middle } \\
\text { Bottom }\end{array}$ & & $\begin{array}{l}5 \\
4\end{array}$ & & & $\begin{array}{l}2 \\
6 \\
1\end{array}$ & & $\begin{array}{l}1 \\
2 \\
1\end{array}$ & 2 & $\begin{array}{l}1 \\
2\end{array}$ & & $\begin{array}{l}2 \\
4 \\
3\end{array}$ & & $\begin{array}{l}1 \\
3\end{array}$ & 1 & 4 \\
\hline $\mathrm{C} 2$ & $\begin{array}{c}\text { Top } \\
\text { Middle } \\
\text { Bottom }\end{array}$ & $\begin{array}{l}2 \\
1 \\
1\end{array}$ & & $\begin{array}{l}2 \\
2 \\
1\end{array}$ & & $\begin{array}{l}3 \\
5 \\
1\end{array}$ & & & $\begin{array}{l}7 \\
2\end{array}$ & & & $\begin{array}{l}2 \\
5 \\
2\end{array}$ & & 1 & 3 & $\begin{array}{l}3 \\
2\end{array}$ \\
\hline C3 & $\begin{array}{c}\text { Top } \\
\text { Middle } \\
\text { Bottom }\end{array}$ & & $\begin{array}{l}2 \\
4 \\
3\end{array}$ & & $\begin{array}{l}1 \\
3\end{array}$ & & $\begin{array}{l}3 \\
2\end{array}$ & $\begin{array}{l}1 \\
3\end{array}$ & $\begin{array}{l}1 \\
1\end{array}$ & $\begin{array}{l}1 \\
2\end{array}$ & & $\begin{array}{l}2 \\
3 \\
4\end{array}$ & & 1 & $\begin{array}{l}1 \\
5\end{array}$ & 2 \\
\hline $\mathrm{C} 4$ & $\begin{array}{c}\text { Top } \\
\text { Middle } \\
\text { Bottom }\end{array}$ & 3 & 2 & 3 & & $\begin{array}{l}2 \\
3 \\
4\end{array}$ & & 1 & $\begin{array}{l}5 \\
2\end{array}$ & 1 & $\begin{array}{l}2 \\
3\end{array}$ & & $\begin{array}{l}1 \\
2 \\
1\end{array}$ & & $\begin{array}{l}3 \\
5 \\
1\end{array}$ & \\
\hline
\end{tabular}


Table C: The number (count), $K_{j}$ out of 9 decisions corresponding to each directional adjustment type $j$. Subject's Classification is determined by all "strong" adjustment types $h: K_{h} \geq 6$ as long as they dominate the best "weak" adjustment types $l: K_{l} \leq 5$ - i.e., $\min _{h}\left[K_{h}\right]-\max _{l}\left[K_{l}\right] \geq 2$. When these conditions fail or there is no strong type, the subject is Unclassified (?).

\begin{tabular}{|c|c|c|c|c|c|c|}
\hline Session & Type & Subject 1 & Subject 2 & Subject 3 & Subject 4 & Subject 5 \\
\hline \multirow{5}{*}{ S1 } & Competitive $(\star)$ & 8 & 8 & - & 8 & 8 \\
\hline & Conformist $(\odot)$ & 2 & 4 & - & 3 & 1 \\
\hline & Pecuniary $(\$)$ & 7 & 6 & - & 7 & 9 \\
\hline & Subject's Classification & $\$ / \star \star$ & $\$ / \star$ & Resolute & $\$ / \star \star$ & $\$ / \star \star$ \\
\hline & Average Giving (St.Err.) & $0.50(0.97)$ & $1.70(2.36)$ & $0(0.00)$ & $0.80(1.32)$ & $0.50(1.58)$ \\
\hline \multirow[t]{5}{*}{ S2 } & Competitive $(\star)$ & 8 & - & - & 7 & 7 \\
\hline & Conformist $(\odot)$ & 0 & - & - & 6 & 5 \\
\hline & Pecuniary $(\$)$ & 9 & - & - & 5 & 6 \\
\hline & Subject's Classification & $\$ / \star \star$ & Resolute & Resolute & $\star / \odot-?$ & $\$ / \star-?$ \\
\hline & Average Giving (St.Err.) & $0.01(0.003)$ & $0(0.00)$ & $0(0.00)$ & $1.35(1.23)$ & $0.575(0.67)$ \\
\hline \multirow[t]{5}{*}{ S3 } & Competitive $(\star)$ & 7 & 4 & 9 & - & 8 \\
\hline & Conformist $(\odot)$ & 3 & 7 & 4 & - & 3 \\
\hline & Pecuniary $(\$)$ & 6 & 2 & 6 & - & 7 \\
\hline & Subject's Classification & $\$ / \star$ & $\odot$ & $\$ / \star$ & Resolute & $\$ / \star$ \\
\hline & Average Giving (St.Err.) & $1.20(1.23)$ & $0.014(0.01)$ & $0.975(1.61)$ & $5.00(0.00)$ & $2.05(2.22)$ \\
\hline \multirow[t]{5}{*}{$\overline{\mathrm{S} 4}$} & Competitive $(\star)$ & 9 & 6 & 4 & 5 & 4 \\
\hline & Conformist $(\odot)$ & 0 & 3 & 5 & 2 & 5 \\
\hline & Pecuniary $(\$)$ & 9 & 5 & 4 & 4 & 4 \\
\hline & Subject's Classification & $\$ / \star$ & $\star-?$ & $?$ & $?$ & $?$ \\
\hline & Average Giving (St.Err.) & $0.007(0.005)$ & $2.07(2.13)$ & $3.10(1.29)$ & $1.026(0.86)$ & $3.30(0.82)$ \\
\hline \multirow[t]{5}{*}{$\overline{\overline{\mathrm{A} 1}}$} & Competitive $(\star)$ & $\overline{9}$ & $\overline{9}$ & - & 4 & - \\
\hline & Conformist $(\odot)$ & 2 & 0 & - & 3 & - \\
\hline & Pecuniary $(\$)$ & 2 & 1 & - & 6 & - \\
\hline & Subject's Classification & $\star$ & $\star$ & Resolute & $\$$ & Resolute \\
\hline & Average Giving (St.Err.) & $6.10(1.10)$ & $6.401(1.15)$ & $0.00(0.00)$ & $2.301(3.43)$ & $0.00(0.00)$ \\
\hline \multirow[t]{5}{*}{ A2 } & Competitive $(\star)$ & 2 & 1 & - & 9 & - \\
\hline & Conformist $(\odot)$ & 2 & 1 & - & 0 & - \\
\hline & Pecuniary $(\$)$ & 8 & 9 & - & 0 & - \\
\hline & Subject's Classification & $\$$ & $\$$ & Resolute & $\star$ & Resolute \\
\hline & Average Giving (St.Err.) & $0.60(1.90)$ & $0.50(1.58)$ & $0.00(0.00)$ & $5.80(0.42)$ & $0.00(0.00)$ \\
\hline \multirow[t]{5}{*}{ A3 } & Competitive $(\star)$ & 1 & 7 & 7 & - & 3 \\
\hline & Conformist $(\odot)$ & 1 & 3 & 3 & - & 1 \\
\hline & Pecuniary $(\$)$ & 8 & 5 & 4 & - & 7 \\
\hline & Subject's Classification & $\$$ & $\star$ & $\star$ & Resolute & $\$$ \\
\hline & Average Giving (St.Err.) & $0.50(1.58)$ & $5.291(1.02)$ & $5.00(3.20)$ & $5.00(0.00)$ & $2.80(3.85)$ \\
\hline \multirow[t]{5}{*}{$\mathrm{A} 4$} & Competitive $(\star)$ & - & 0 & 9 & 4 & 8 \\
\hline & Conformist $(\odot)$ & - & 0 & 4 & 4 & 4 \\
\hline & Pecuniary $(\$)$ & - & 9 & 4 & 6 & 5 \\
\hline & Subject's Classification & Resolute & $\$$ & $\star$ & $\$$ & $\star$ \\
\hline & Average Giving (St.Err.) & $5.00(0.00)$ & $0.30(0.95)$ & $5.00(1.94)$ & $1.50(1.90)$ & $5.575(0.54)$ \\
\hline
\end{tabular}


Table D: Summary of giving by directional adjustment types for the Selfish (S) and Altruistic (A) treatments.

\begin{tabular}{|c|c|c|c|c|}
\hline Subject's Type & Subject & Period 1 & Periods $2-10$ & All periods \\
\hline S-Resolute & Average $(\mathrm{N}=4)$ & 1.25 & 1.25 & 1.25 \\
\hline S-Pecuniary/Competitive (S\$/^) & Average $(\mathrm{N}=9)$ & 2.891 & 0.634 & 0.859 \\
\hline S-Pecuniary/Competitive (S\$/*) & $\mathrm{S} 1-1$ & 3 & 0.222 & 0.5 \\
\hline S-Pecuniary/Competitive $(\mathrm{S} \$ / \star)$ & S1-2 & 5 & 1.333 & 1.7 \\
\hline S-Pecuniary/Competitive $(\mathrm{S} \$ / \star)$ & S1-4 & 0 & 0.889 & 0.8 \\
\hline S-Pecuniary/Competitive (S\$/*) & S1-5 & 5 & 0 & 0.5 \\
\hline S-Pecuniary/Competitive (S\$/*) & $\mathrm{S} 2-1$ & 0.01 & 0 & 0.001 \\
\hline S-Pecuniary/Competitive (S\$/*) & S3-1 & 3 & 1 & 1.2 \\
\hline S-Pecuniary/Competitive (S\$/*) & S3-3 & 5 & 0.528 & 0.975 \\
\hline S-Pecuniary/Competitive (S\$/*) & S3-5 & 5 & 1.722 & 2.05 \\
\hline S-Pecuniary/Competitive (S\$/*) & S4-1 & 0.01 & 0.007 & 0.007 \\
\hline S-Unclassified (S?) & Average $(\mathrm{N}=7)$ & 2.931 & 1.489 & 1.634 \\
\hline S-Unclassified (S?) & $\mathrm{S} 2-4$ & 3 & 1.167 & 1.35 \\
\hline S-Unclassified (S?) & $\mathrm{S} 2-5$ & 2 & 0.417 & 0.575 \\
\hline S-Unclassified (S?) & S3-2 & 0.02 & 0.013 & 0.014 \\
\hline S-Unclassified (S?) & S4-2 & 3.5 & 1.911 & 2.07 \\
\hline S-Unclassified (S?) & S4-3 & 5 & 2.889 & 3.1 \\
\hline S-Unclassified (S?) & S4-4 & 2 & 0.918 & 1.026 \\
\hline S-Unclassified (S?) & S4-5 & 5 & 3.111 & 3.3 \\
\hline A-Resolute & Average $(\mathrm{N}=6)$ & 1.67 & 1.67 & 1.67 \\
\hline A-Pecuniary $(\mathrm{A} \$)$ & Average $(\mathrm{N}=7)$ & 3.286 & 0.984 & 1.214 \\
\hline A-Pecuniary $(\mathrm{A} \$)$ & $\mathrm{A} 1-4$ & 5 & 2.001 & 2.301 \\
\hline A-Pecuniary $(\mathrm{A} \$)$ & $\mathrm{A} 2-1$ & 0 & 0.667 & 0.6 \\
\hline A-Pecuniary $(\mathrm{A} \$)$ & A2-2 & 5 & 0 & 0.5 \\
\hline A-Pecuniary (A $\$$ ) & A3-1 & 0 & 0.556 & 0.5 \\
\hline A-Pecuniary $(\mathrm{A} \$)$ & A3-5 & 5 & 2.556 & 2.8 \\
\hline A-Pecuniary $(\mathrm{A} \$)$ & $\mathrm{A} 4-2$ & 3 & 0 & 0.3 \\
\hline A-Pecuniary $(\mathrm{A} \$)$ & $\mathrm{A} 4-4$ & 5 & 1.111 & 1.5 \\
\hline A-Competitive $(\mathrm{A} \star)$ & Average $(\mathrm{N}=7)$ & 5.071 & 5.653 & 5.595 \\
\hline A-Competitive $(A \star)$ & $\mathrm{A} 1-1$ & 5 & 6.222 & 6.1 \\
\hline A-Competitive $(A \star)$ & A1-2 & 5 & 6.557 & 6.401 \\
\hline A-Competitive $(A \star)$ & A2-4 & 5 & 5.889 & 5.8 \\
\hline A-Competitive $(A \star)$ & A3-2 & 6 & 5.212 & 5.291 \\
\hline A-Competitive $(A \star)$ & A3-3 & 5 & 5 & 5 \\
\hline A-Competitive $(A \star)$ & $\mathrm{A} 4-3$ & 5 & 5 & 5 \\
\hline A-Competitive $(A \star)$ & $\mathrm{A} 4-5$ & 4.5 & 5.694 & 5.575 \\
\hline
\end{tabular}




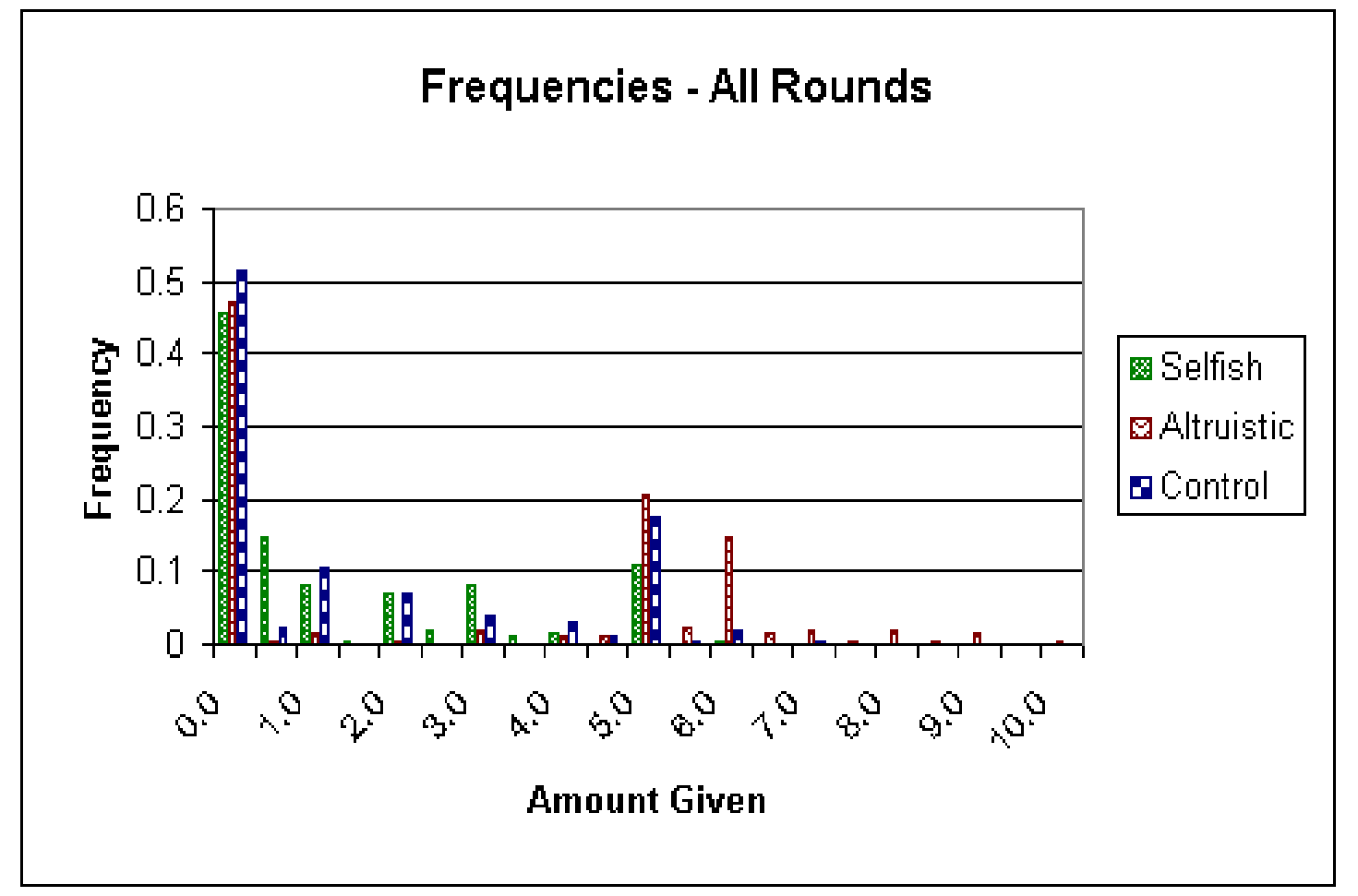

a) Frequency distributions;

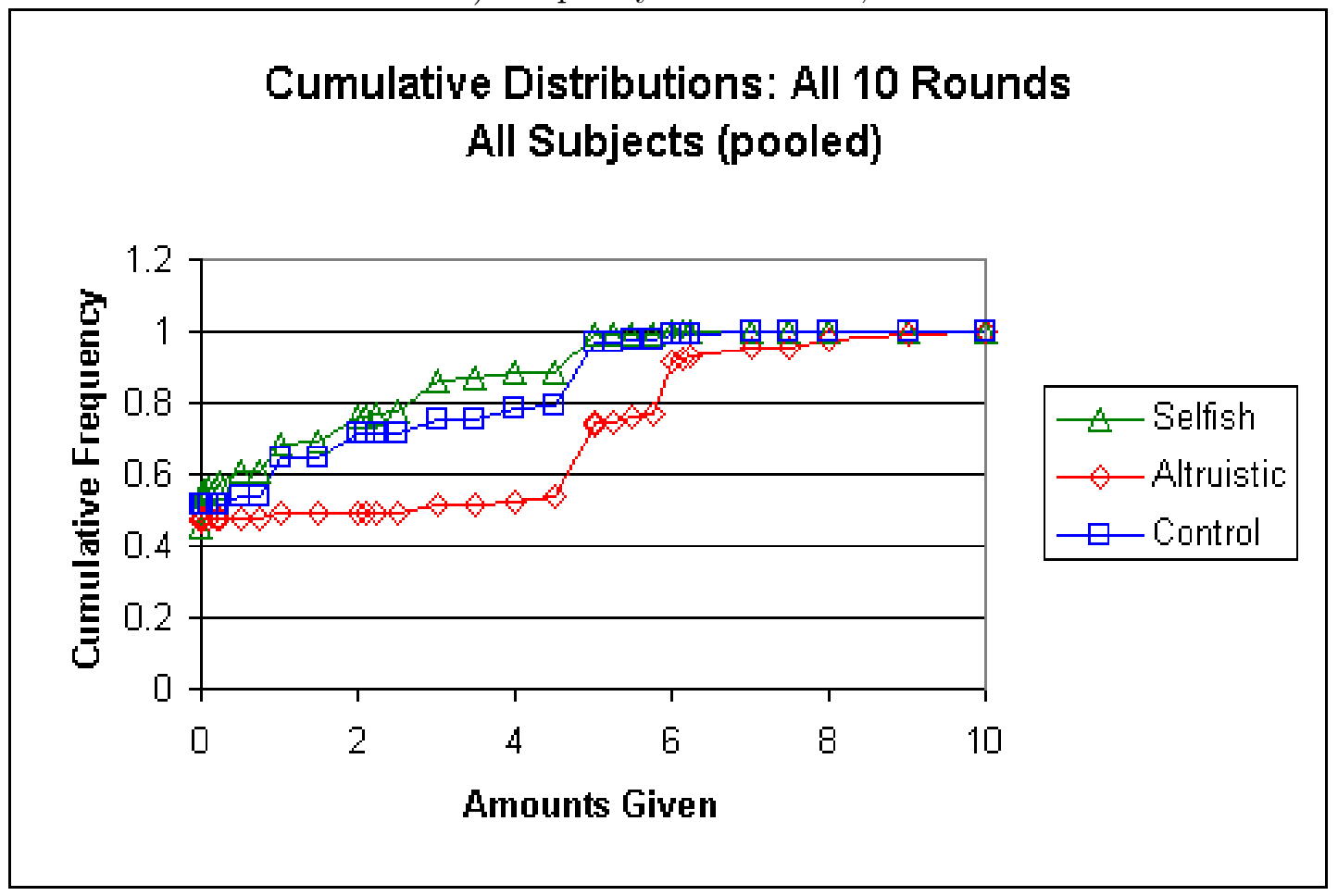

b) Cumulative distributions.

Figure 1: Distributions of giving for all observations. 


\section{Proportion of subjects giving $\$ 1$ or less}

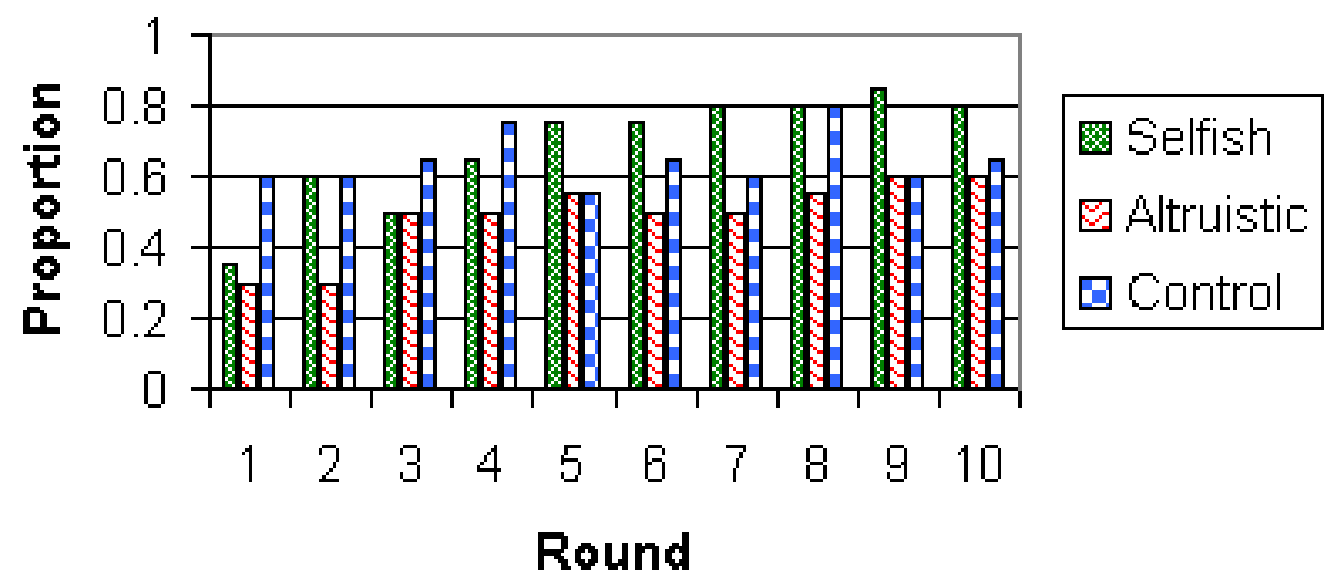

a) Self-regarding subjects;

\section{Proportion of subjects giving $\$ 5$ and more}

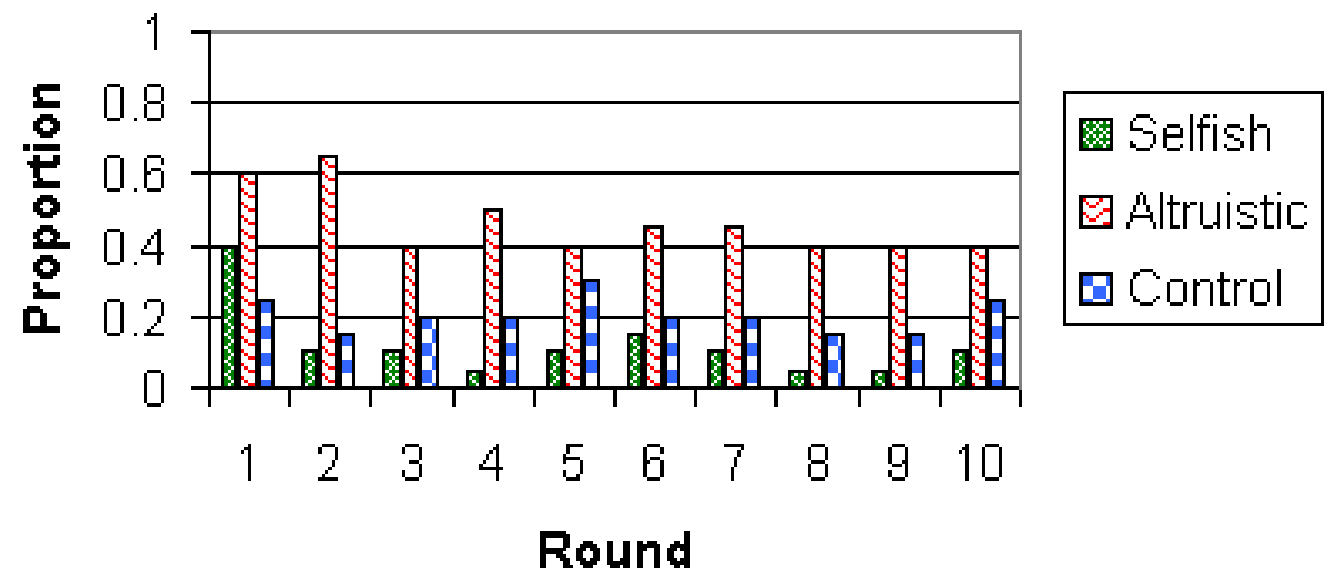

b) Other-regarding subjects.

Figure 2: Proportion of subjects giving $\$ 1$ and less (self-regarding) and $\$ 5$ and more (otherregarding). 


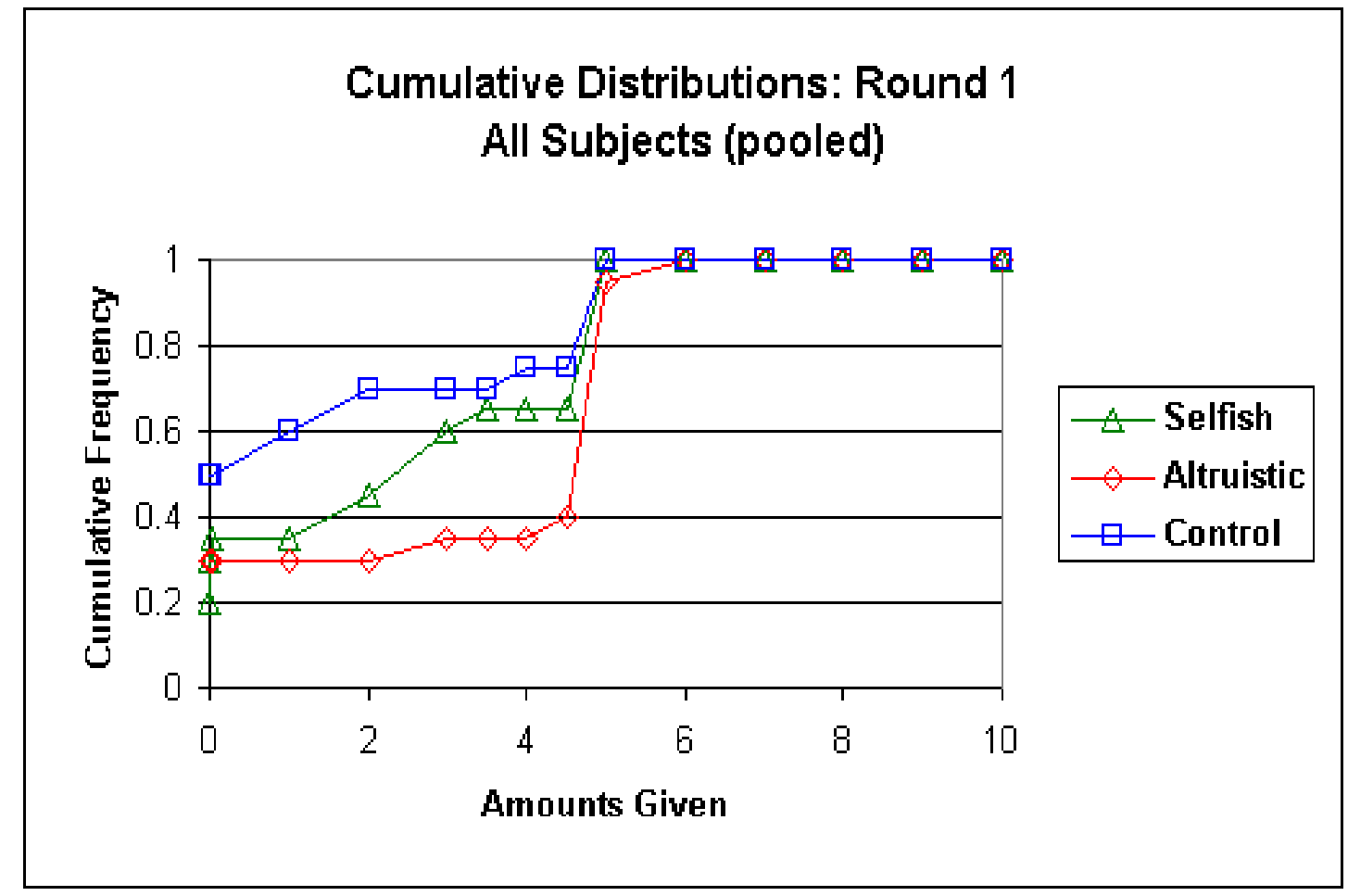

a) Cumulative distributions for Round 1;

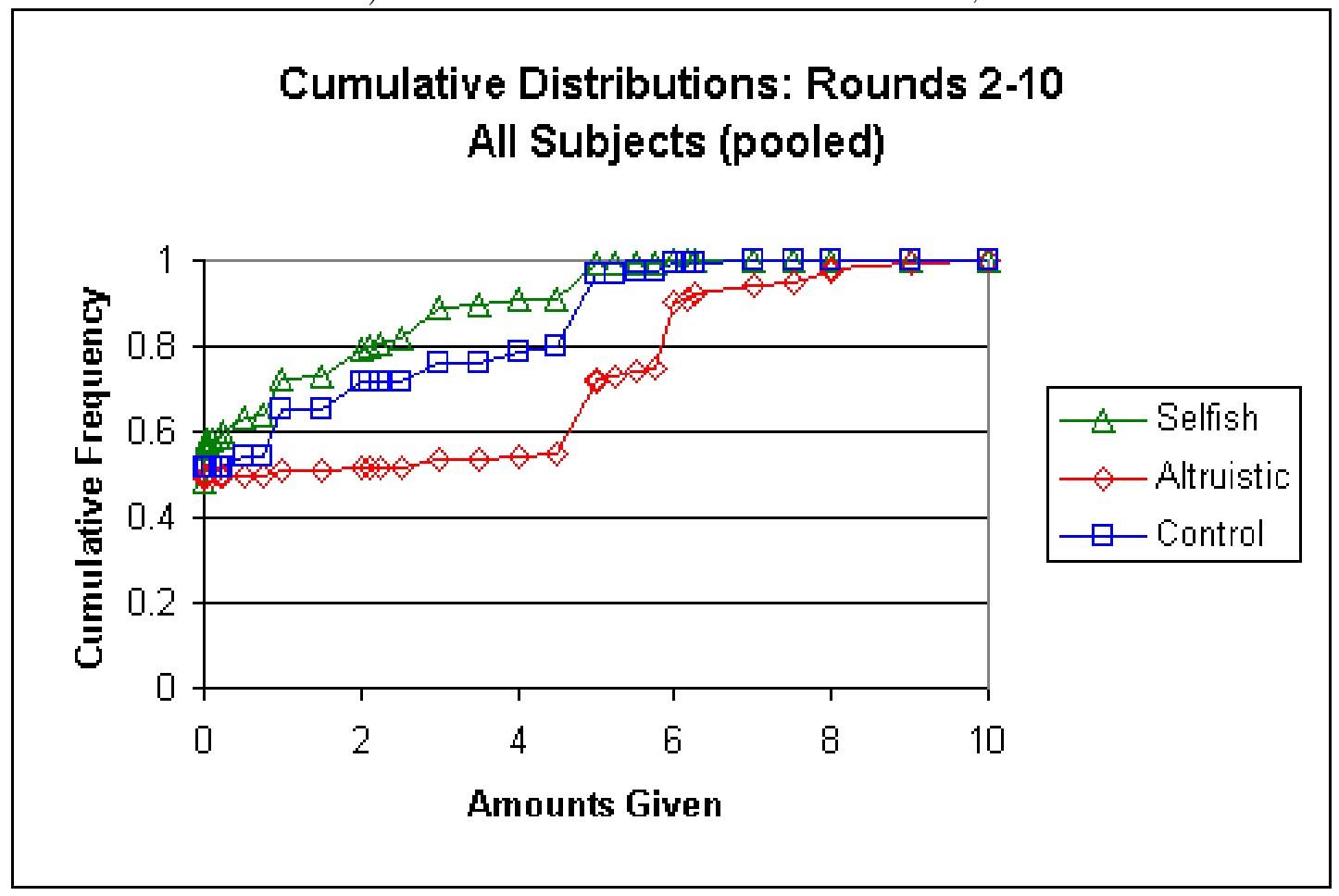

b) Cumulative distributions for Rounds 2-10.

Figure 3: Cross-treatment comparison of all subjects' giving in the Round 1 and Rounds $2-10$. 


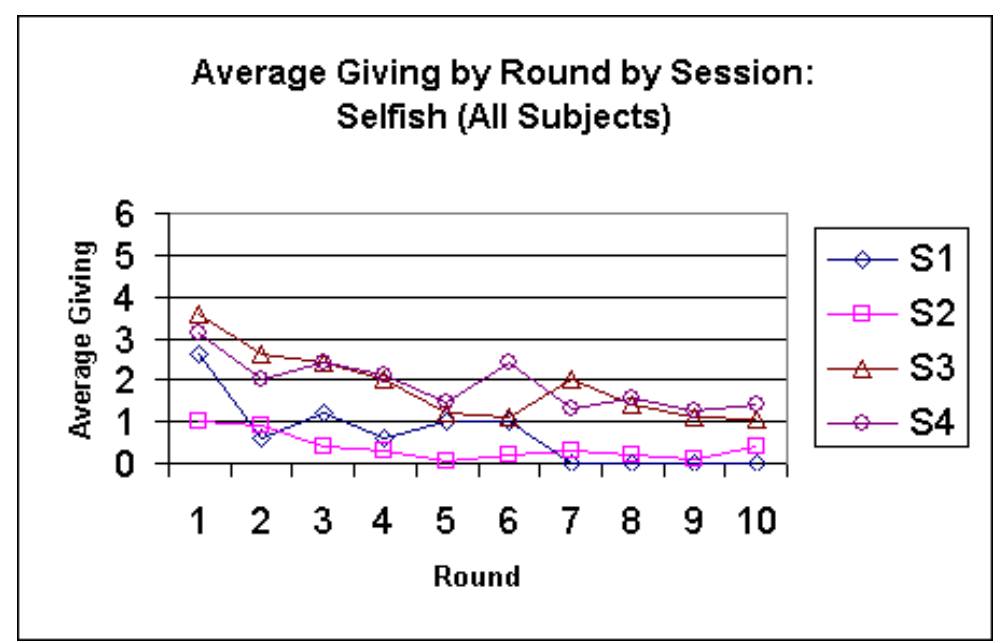

a) Selfish Treatment

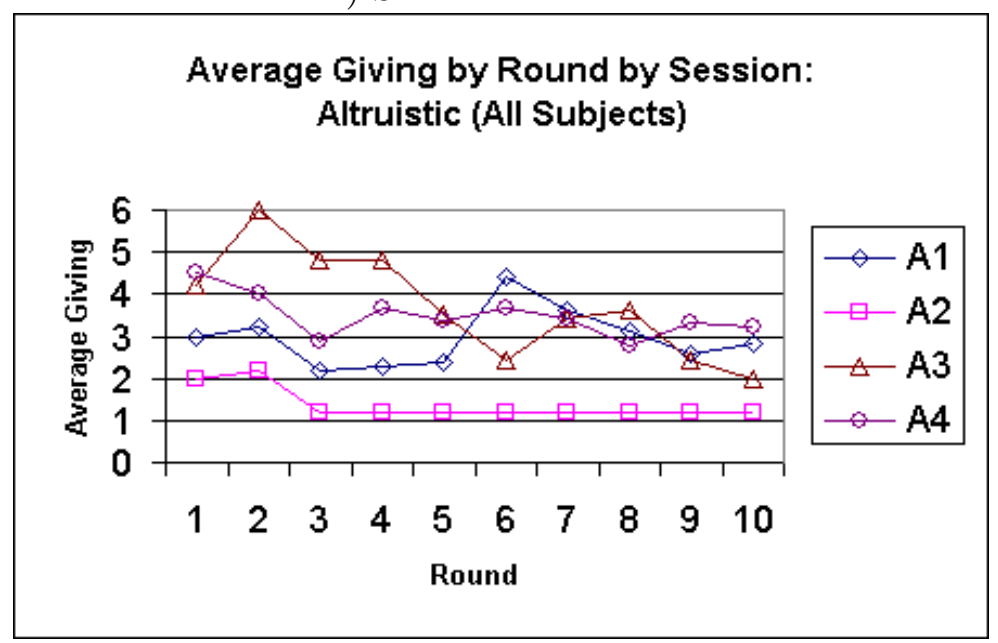

b) Altruistic Treatment

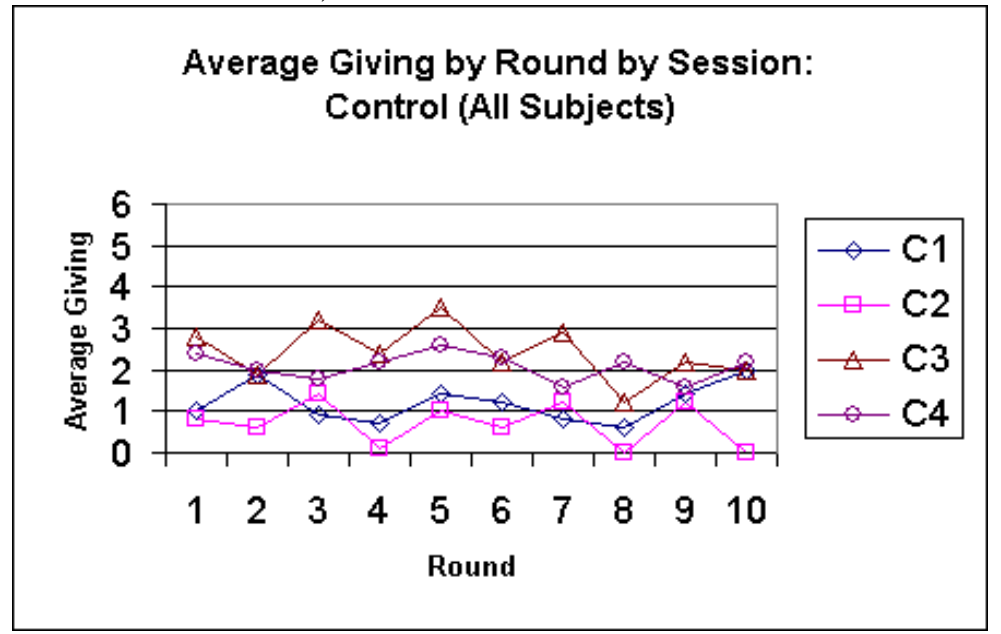

c) Control Treatment

Figure 4: Average per round giving for each session for all subjects. 


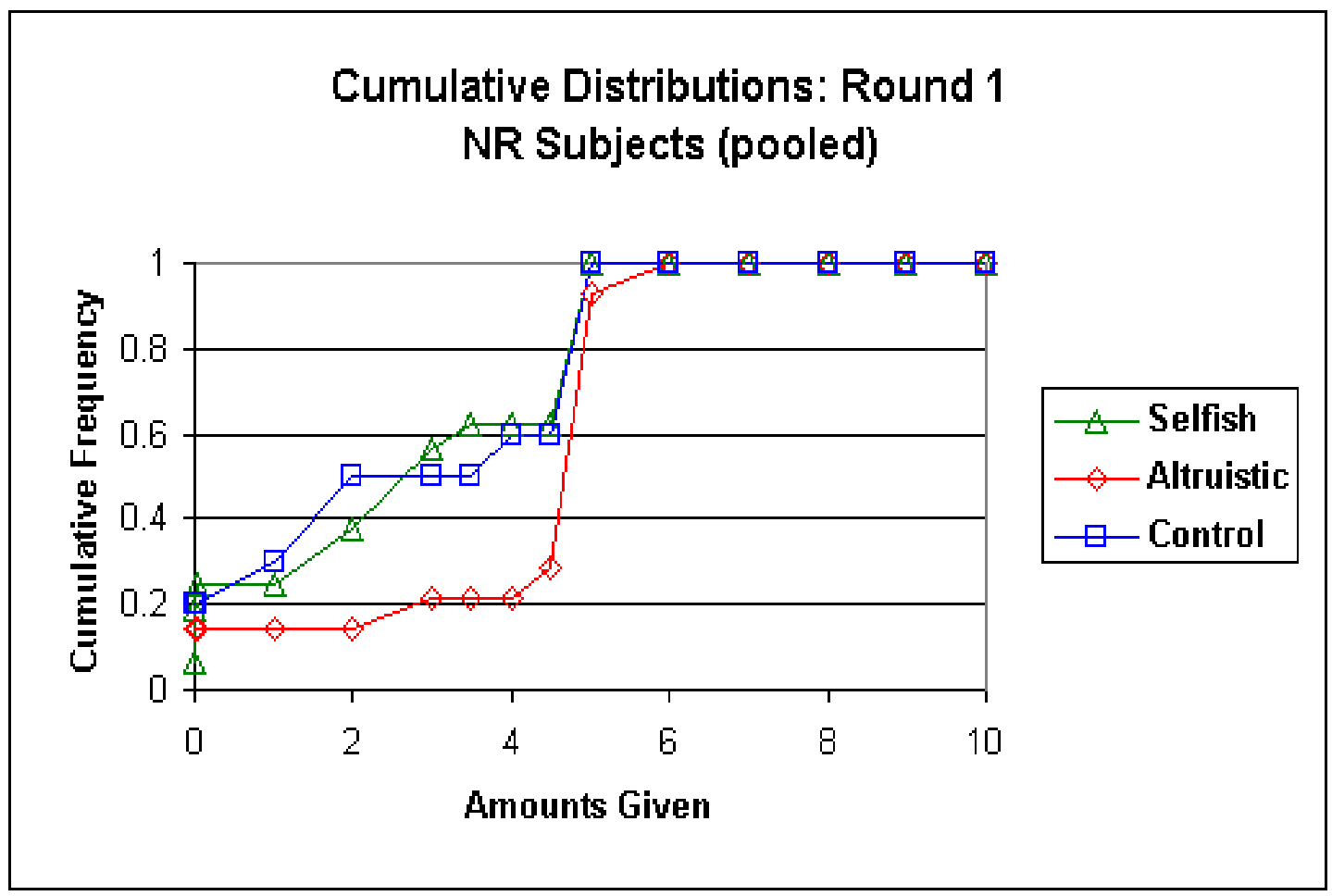

a) Cumulative distributions for Round 1;

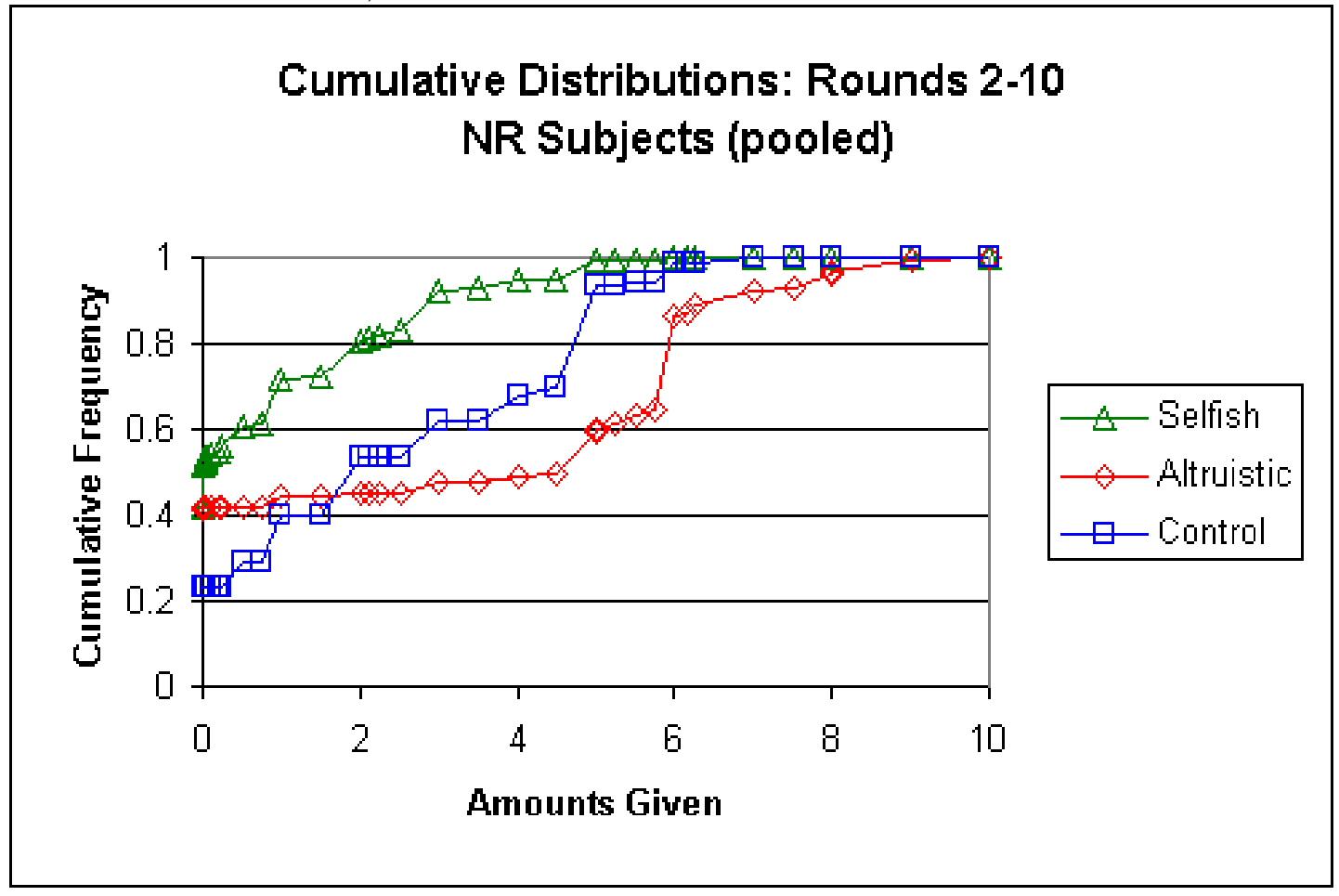

b) Cumulative distributions for Rounds 2-10.

Figure 5: Cross-treatment comparison of Non-Resolute subjects' giving in the Round 1 and Rounds 2-10. 


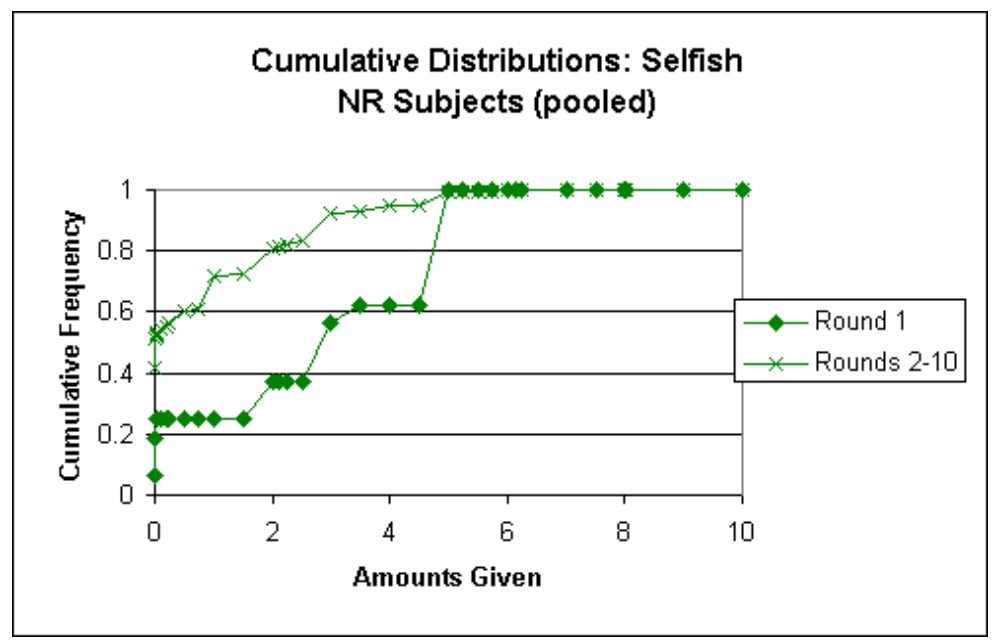

a) Selfish Treatment

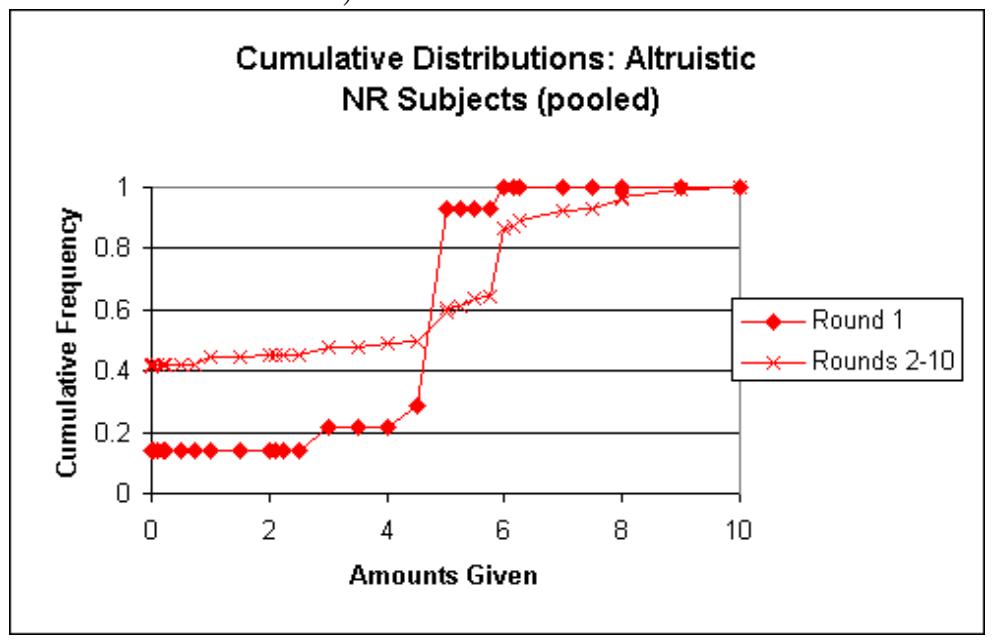

b) Altruistic Treatment

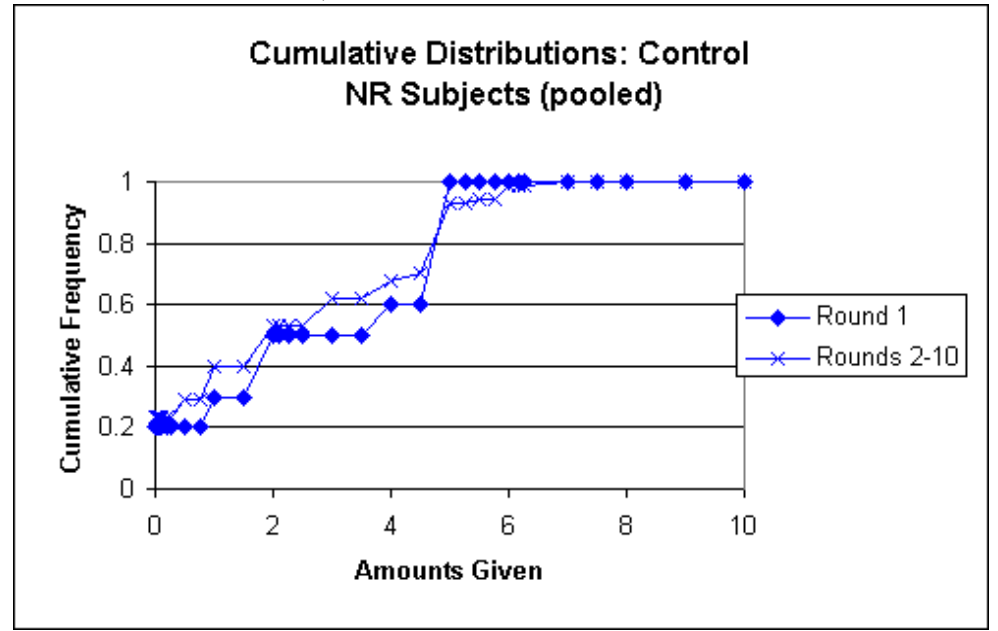

c) Control Treatment

Figure 6: Within treatment comparison of Non-Resolute subjects' giving in Round 1 and Rounds 2-10. 